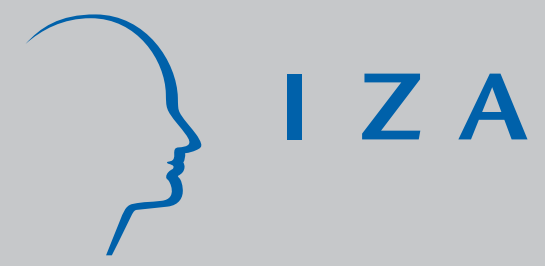

IZA DP No. 5292

With or Without You:

Divorce Rates and Intra-Household Allocation of Time

Domenico Tabasso

October 2010 


\title{
With or Without You: Divorce Rates and Intra-Household Allocation of Time
}

\author{
Domenico Tabasso \\ MIAESR, University of Melbourne \\ and IZA
}
Discussion Paper No. 5292
October 2010

\author{
IZA \\ P.O. Box 7240 \\ 53072 Bonn \\ Germany \\ Phone: +49-228-3894-0 \\ Fax: +49-228-3894-180 \\ E-mail: iza@iza.org
}

Any opinions expressed here are those of the author(s) and not those of IZA. Research published in this series may include views on policy, but the institute itself takes no institutional policy positions.

The Institute for the Study of Labor (IZA) in Bonn is a local and virtual international research center and a place of communication between science, politics and business. IZA is an independent nonprofit organization supported by Deutsche Post Foundation. The center is associated with the University of Bonn and offers a stimulating research environment through its international network, workshops and conferences, data service, project support, research visits and doctoral program. IZA engages in (i) original and internationally competitive research in all fields of labor economics, (ii) development of policy concepts, and (iii) dissemination of research results and concepts to the interested public.

IZA Discussion Papers often represent preliminary work and are circulated to encourage discussion. Citation of such a paper should account for its provisional character. A revised version may be available directly from the author. 


\section{ABSTRACT \\ With or Without You: Divorce Rates and Intra-Household Allocation of Time*}

This paper investigates the relationship between the probability of divorce and marriage specific investments. As these investments in terms of childcare and household activities are likely to increase the marital surplus, they are consequently likely to decrease the risk of divorce. All such activities, however, are characterized by gender role bias through, for example, social norms. In periods in which married women enjoy greater outside options (e.g., by increasing their labor force participation), it is expected that households in which the husband takes on typically female chores are less likely to dissolve, while couples in which the wife takes on typically male chores are more likely to divorce. The paper tests this hypothesis using data from the National Longitudinal Survey (NLS) of Mature Women, the NLS Young Women, and the NLSY79. The prediction is strongly supported by the data with respect to older cohorts while it loses empirical relevance when tested on younger individuals. Furthermore, asymmetric effects between genders gain importance over time. Finally, an explanation for the relationship between divorce and marital investments is offered in terms of increasing intra-household time consumption complementarities. To this end, data from the American Time Use Surveys from 1965 to 2005 are studied to illustrate how time spent together by partners in the same household has become increasingly crucial in the American family.

JEL Classification: J12, J13, D12

Keywords: marital market, leisure, time use, survival analysis

Corresponding author:

Domenico Tabasso

Melbourne Institute of Applied Economic and Social Research

The University of Melbourne

Parkville, Victoria 3010

Australia

E-mail: dtabasso@unimelb.edu.au

\footnotetext{
* This paper has been written during my period of doctoral studies at the University of Essex. I am strongly indebted to my PhD supervisor, Marco Francesconi. I would also like to thank Patrick Nolen, Andrew Oswald and Joao Santos Silva for useful conversations on the topic and the seminar participants at University of Essex, ESPE Conference, EALE Conference, AIEL Conference, SAEe Conference and IZA Bonn for their comments. On the early stages of this work I also benefited from valuable suggestions from Robert Pollak. All mistakes are of course my full responsibility.
} 


\section{Introduction}

Marital unions are often described in Economics as finding their rationale in the specific investment partners undergo with the aim of building a marital surplus which substantiates itself in the consumption of a public good produced within the household. As an example, the effort exerted by parents in the education of children has very often been seen as a natural representation of the way partners can contribute to the shaping of a union-specific marital capital ${ }^{1}$. The aim of this paper consists in investigating the link between the extent and the nature of spouses' commitments in the development of an intra-household surplus and the likelihood of success of the marital union. In pursuing this goal, two features characterizing the process of creation of a marriage-specific capital need to be accounted for. First of all, the investments that lead to the formation of a marital surplus are heavily influenced by a gender role bias that reverberates the effects of social norms in the management of household activities. Several studies on the inter-temporal allocation of time and on the evolution of female labour supply have shown that the incidence of time devoted to household activities still plays an important role in the determination of female career profiles ${ }^{2}$. Furthermore, as in most contemporary societies marriages are not linked to binding agreements and the observability of the individual contribution to the public good consumed within the household is limited ${ }^{3}$, the relation between the duration of a marriage and the individual investment is rarely perfectly identifiable $^{4}$. In this paper, a direct connection between household management and divorce is empirically established and the inter-temporal relevance of different patterns of time investment is assessed in relation to their relative explanatory power of the hazard of marital separation.

More specifically, in the present work marital specific investments are defined according to the way spouses share responsibilities for household chores and childcare and two sets of "female dominated" and "male dominated" activities are identified. It is then assumed that households in which the husband takes on typically female chores are less likely to dissolve, while couples in which the wife takes on typically male chores are more likely to divorce. This prediction is tested using

\footnotetext{
${ }^{1}$ Most of the existing literature in this fields finds its starting point in the seminal contributions of Becker (1973), Becker (1974), Becker (1981).

${ }^{2}$ The literature on social norms and on the female labour supply is extremely rich. Among others, the contributions of Gronau (1980) and more recently Blau and Kahn (2007) and Burda, Hamermesh, and Weil (2007) are certainly worth to be mentioned. A theoretical characterization of the effects of social norms on the labour market outcome is given by Akerlof (1980) and Lindbeck (1997).

${ }^{3}$ See Lundberg and Pollak (1993).

${ }^{4}$ Several models have been developed in which bargaining over the optimal level of resources to be invested in the quality of the public good occurs between spouses, possibly allowing for divorce as a way to resolve unsatisfactory matches. A representative example can be found in Weiss and Willis (1985).
} 
data from the National Longitudinal Survey (NLS) of Mature Women, the NLS of Young Women and the NLSY79 complemented with data from the American Time Use Surveys (ATUS). The multiplicity of datasets allows for the introduction of an inter-temporal dimension in the analysis, which can be performed on three different cohorts of individuals on a length of time spanning from the mid-Sixties to the early years of the present decade. This element proves to be particularly relevant for the effective development of the proposed empirical strategy as the estimated results suggest that the link between the way partners share household responsibilities and the hazard rate of divorce has changed considerably over time. In particular, although the involvement of men in the performance of household activities, measured by the amount of time daily devoted to them, has dramatically increased during the last forty years, the explanatory power of male participation to house chores over the likelihood of divorce proves to be particularly strong only with respect to the older cohorts of sampled individuals. Conversely, the empirical linkage between hazard of divorce and male participation in female dominated activities tends to vanish in the most recent surveys.

All the findings based on the NLS data contribute to question the possibility to evaluate the probability of success of a marital union according to the theory of production complementarities, as developed by Gary Becker ${ }^{5}$, and which are still at the base of a number of studies on the determinants of marriage and divorce ${ }^{6}$. In the final part of the paper I enlarge the scope for complementarities within the household, stressing the importance of the possibility for couples to enjoy the simultaneous consumption of goods. The partnership formed in the wedlock is then observed as a "consumption unit" instead of a mere production center. The vector of goods to be included in the feasible set is to be intended in a relatively broad sense. Due to data availability, the focus of the paper will be on the consumption of time. In this respect, the present work can be located in the same strand of literature on togetherness as developed in Hamermesh (2002) and Hamermesh (2007). The very same decision of getting married (and hence that of divorcing) directly depends not just on the way the partners complement each other in the abilities to produce income and goods to be consumed in the household, but also (and perhaps more importantly) on

\footnotetext{
${ }^{5}$ See, among several contributions,Becker (1981), Becker (1973), Becker (1974), Becker, Landes, and Michael (1977).

${ }^{6}$ See, for example, Anderson and Little (1999), Baker and Jacobsen (2007), Cherlin (2004), Pollak (2003). The contribution of Becker is mainly based on frictionless framework, which leads toward positive assortative matching (see Becker (1973) and Becker (1991)). Shimer and Smith (2000) and Smith (2006) show under which conditions positive (or negative) assortative matching can still be achieved when the hypothesis of frictionless matching is challenged.
} 
their forecast on the activities they will perform together, on the quality, and not on the quantity, of the time they intend to consume while simultaneously engaged in the same activities.

The proposed characterization should not be seen as alternative to what suggested by the already established theories on marriages and divorce ${ }^{7}$. Conversely, my contribution goes toward an enrichment of these theories, although I favor an empirical approach. Relying again on the ATUS data the existence of substantial changes in the way American couples spend their time together over the last forty years is tested. The results show that the way partners spend their time when together has changed over the considered time horizon. Although the total amount of time spent together has decreased in the last thirty years, the data show a sensible increase in the time being devoted to joint leisure activities. On the contrary, the time patterns in the link between togetherness and the time variables related to house activities and child care varies depending on sex of the respondent.

The paper is organized as follows: in the next two sections I will briefly analyze some of the contributions in the literature and the differences between the theoretical context of the present work and the existing models. I will then describe the datasets I use and expose the methodology I will rely on for the empirical analysis, which is presented in section 5. Section 6 concludes.

\section{Preliminary Evidence and Related Literature}

Table 1 presents some evidence regarding the average amount of time (in minutes per day) spent in household chores and childcare by married individuals in the US in the last forty years. The data come from the American Time Use Surveys and show that in the last decade American men spend half an hour more in both activities with respect to the Sixties, while for women the time devoted to household chores has dramatically decreased and the trend in childcare does not follow a monotonic pattern. The observation of these figures, which confirm the findings of Aguiar and Hurst (2007), should be enough to question the possibility to mechanically apply to contemporary American families models and analyses purely based on the role of production complementarities and comparative advantages within households. The empirical investigation on the forces behind the decision to divorce presented in section 4 and the introduction of time use complementarities as a way to explain the American data represent an attempt, with no presumption of completeness,

\footnotetext{
${ }^{7}$ Good surveys on the theoretical approaches on divorce are presented in Weiss (1997) and Bergstrom (1996).
} 


\begin{tabular}{lccccc}
\hline \hline & $\mathbf{1 9 6 5}$ & $\mathbf{1 9 7 5}$ & $\mathbf{1 9 8 5}$ & $\mathbf{2 0 0 3}$ & Diff.03-65 \\
\hline Males & & & & & \\
House Chores & 41.949 & 65.317 & 70.527 & 75.706 & 33.756 \\
& 74.49 & 106.3 & 98.85 & 111.14 & \\
Childcare & 16.612 & 17.843 & 17.681 & 46.404 & 29.793 \\
& 33.55 & 44.47 & 41.22 & 86.96 & \\
\hline Females & & & & \\
House Chores & 266.105 & 190.778 & 188.519 & 149.539 & -116.566 \\
& 139.0 & 134.0 & 127.49 & 129.6 & \\
Childcare & 72.9 & 56.2074 & 58.974 & 94.884 & 21.984 \\
& 45.99 & 54.16 & 58.97 & 69.66 & \\
\hline All differences presented in the last column are statistically significant at 1\% level. \\
Standard deviations into brackets.
\end{tabular}

Table 1: Average Time per Day (in Minutes)

to develop an alternative way of looking at intra-household dynamics.

The number of studies that have already tackled the issues of marriage and divorce is of course extremely relevant ${ }^{8}$. The main aim of my paper is to explore the reasons behind divorce, and thus it focuses on the causes of marital separations. The impact of changes in legislations on the number of divorces per year, for example, is a (to some extent controversial) topic to which scholars have devoted much attention. The introduction of the regime of unilateral divorce, which almost simultaneously occurred in the majority of the United States at the end of the 60's, provided a natural experiment on the impact of this kind of shifts in laws. The apparently logical link between the number of divorces per year and the increased easiness in the achievement of the legal ending of a marriage has not been confirmed in all studies looking at law changes. For instance, the findings of Friedberg (1998), who argues that the relation between the new legislation and the divorce rate is strongly positive, have been contradicted by Wolfers (2006), whose findings suggests that such a relation may only be valid in the short run, and by Gray (1998), for whom the impact of the legislative change is to be studied with respect to a shift in the female labour supply and not in the divorce rate tout-court ${ }^{9}$. Rasul (2006b) even argues that the introduction of unilateral divorce resulted in a decrease of the divorce rate, by increasing the probabilities of better matchings in the

\footnotetext{
${ }^{8}$ Among several contributions it is certainly worth to mention Lundberg and Pollak (1994), Bergstrom (1996), Browning and Chiappori (1998), Browning, Chiappori, and Lechene (2006), Lundberg and Pollak (2007).

${ }^{9}$ The effect of the introduction of unilateral divorce on the female labour supply is also the main focus of Stevenson (2007).
} 
marital market.

Similar disagreements exist with regards to studies on self-selection into the marital market. In particular, the increasing importance that cohabitation has recently gained importance as an alternative to marriage ${ }^{10}$ has led some analysts to assume that a prolonged pre-nuptial cohabitation period would at least partly guarantee the minimization of the "learning effect" problem which can in some cases drive the decision to divorce. Nonetheless, Barham, Devlin, and Yang (2009) provide a theoretical framework within which the decision of getting married after a period of cohabitation can be optimal even if the partners are already certain that it will lead to divorce. From an empirical perspective, Thomson and Colella (1992), Lillard, Brien, and Waite (1995) and more recently Dush, Cohan, and Amato (2003) have shown how couples which have experienced cohabitation before marriage tend to have low quality marital experiences and a higher likelihood of divorce (Brines and Joyner (1999) argue that the probability of separation is affected by a long period of cohabitation only if the partners are married, not if they cohabit). These contributions aim at studying the dynamics of the marital market through the learning effects that certainly characterize partnerships but which can only partly explain the set of reasons that may lead to the end of a marriage. Burdett and Coles (1998), for example, suggest two more motivations for divorce. Married couples may opt out of the wedlock after a change in the payoff related to the outside option (either being single or starting a new relationship) and if there is a change in the productivity of the match. The explicit introduction of the three reasons for a divorce (learning effects, changes in the match productivity and changes in the outside options) is found in a number of papers which tackle the issue of marital separation using a search and matching approach. A multiplicity of equilibria spanning from cases in which separation is never possible to cases in which divorce is taking into consideration even in the case of a good quality match are often the outcomes of these analyses, among which it is worth to mention Burdett, Imai, and Wright (2004) and Cornelius (2003) ${ }^{11}$. Most of these studies assume that divorce is an event which might occur, but refrain from analysing the causes which can induce such a choice. In this respect, my paper tries to go beyond the mechanics of marital separation, in order to focus on the dynamics characterizing the relation between causes of divorce and its occurrence.

\footnotetext{
${ }^{10}$ Some basic evidence on this can be found in Cherlin (2004).

${ }^{11}$ Mortensen (1988) provides a good review of the benefits and the limits of the application of matching models to marital markets.
} 


\section{The Changes in Time Management and their Effects on Couples}

Within the economic literature the process of formation of families is usually summarized by the assumption that "[C]ouples marry and stay married when the gains from marriage exceed the gains from being single" ${ }^{\prime 2}$. The relation between the occurrence of marriages and divorces and the utility achieved by the partners is therefore pivotal for the survival probabilities of marital relationships. Nonetheless, what determines the level of utility achieved by the couple is not totally clear. Following Becker (1991), a relevant number of contributions have focused on the way spouses produce the public good whose consumption determines the utility level of the couple. In this respect, the division of labour within the family has been studied, with reference to the theory of comparative advantages and specialization in households, while the modes of consumption of the public good are generally neglected. The analysis proposed by Goldin (2006), which investigates the female labour supply in the United States from the end of the nineteenth century to present time, clearly indicates how the amount of time women devote to labour market has been steadily increasing from the end of the Second World War until mid-Nineties, and has only recently started to stabilize. This increase has been accompanied by an improvement in females' education and a rise in women salaries, which have made time spent in household chores relatively more expensive, and an increase in the average age at first marriage. Moreover Aguiar and Hurst (2007) show that the time spent in leisure activities by married individuals has increased during the last four decades thanks to a reduction in work hours for men and to a decrease in the time spent in household chores for women. The simultaneous occurrence of all these phenomena certainly contributed to the establishment of new patterns of time consumptions within families, although the effects of these changes have certainly not been homogeneous across households. It appears therefore natural to study the likelihood of divorce in relation to the development of these new forms of household management. The analysis is based on the explicit assumption that different ways to share the responsibilities of the main household tasks can be directly linked to the success of the marital union and not only implies that the contribution of each spouse to these activities can explain the formation of a marital-specific capital, but it necessarily relates the success of a marriage to the observability

\footnotetext{
${ }^{12}$ Stevenson and Wolfers (2007), p.40.
} 
of the effort exerted by each partner in the creation of the public $\operatorname{good}^{13}$. Furthermore, a model of allocation of time in which men tend to increase their involvement in household chores leads to the need for an investigation on the way individuals extract utility from their marital partnerships. Hamermesh (2002) proposes the explicit introduction of the time spent together by partners in the utility function of the household in order to establish a correlation between togetherness and gains from marriage. His conclusion is that partners' time is complementary in the sense that spouses are better off "having the possibility to consume time together" ${ }^{14}$. The possibility to study divorce rates in terms of their relation with the way partners split the chores and the possible emergence of time use complementarities is strictly connected to Hamermesh's point of view and represents the main focus of this paper. In the same spirit as in Stevenson and Wolfers (2007), consumption complementarities are defined as the extent of the spouses' joint consumption of public goods and quality time and are approximated by the amount of time devoted to shared leisure activities. The effectiveness of projecting the phenomenon of jointness in consumption onto the probability of divorce relies on a set of theoretical and methodological assumptions. In particular, the utility function of each partner needs to capture the desire for the joint consumption of leisure time. If we assume that the utility of an individual is increasing in the consumption of leisure, togetherness per se should imply that each partner is strictly better off when consuming leisure with the spouse than alone ${ }^{15}$. The benefit that partners can extract from the joint consumption of "quality time" goes beyond the simple summation of the individual benefit from leisure time and in this sense can be seen as a driving force toward the establishment of complementarities. The ability of couples to extract marginal utility gains from the time spent together is then to be interpreted as an indication of the quality of the match, whose realization determines the stability of the partnership ${ }^{16}$.

Although an investigation on the relation between time spent together and success of a match can appear redundant with respect to the reality of Western countries, a number of issues may still affect the effective transposition of the above theoretical claims onto an empirical research. First

\footnotetext{
${ }^{13}$ Rasul (2006a) and Francesconi and Muthoo (2003) provide models in which the optimal allocation of resources in terms of child custody in case of divorce is explicitly linked to the lack of control over the action of the counterpart in the fulfillment of a contractual agreement. In this respects these contributions relate their findings to literature on contractual hold-up, as in Hart (1995), ch.4 and Laffont and Martimort (2002), ch.9.

${ }^{14}$ Hamermesh (2002), p.617.

${ }^{15}$ If we assume the utility of an individual only depends on her consumption of leisure time and on the state of the world $s$, where $s=1$ if the partner is present at time of consumption, $s=0$ otherwise, then togetherness can be expressed as $u(l, 1)>u(l, 0)$ and $u^{\prime}(l, 1)>u^{\prime}(l, 0)$.

${ }^{16}$ Fernandez, Guner, and Knowles (2005) implicitly introduce the quality of the match in the couple indirect utility, according to the following quasi-linear specification: $V(I, q)=u(I)+q$ where $q$ is the quality of the match and $u(I)$ is a (strictly increasing) function of the family income.
} 
of all, it is not possible to rule out the possibility that couples exist in which partners prefer not to spend their quality time together. In this respect, the possibility to rely on well established datasets characterized by numerically relevant samples guarantees the achievement of relatively robust results. Furthermore, no claims can of course be made in terms of the existence of any causality between the extent of jointness and the trends in divorce rates given the obvious relevance of the issue of endogeneity. These points will be taken into consideration within the proposed empirical analysis through various specification robustness checks.

\section{The Data}

\subsection{The National Longitudinal Survey}

As the core of the empirical analysis proposed in section 4 consists in the investigation of the linkage between the allocation of household responsibilities and the likelihood of divorce across different decades, it is natural to rely on longitudinal data in order to fully explore the inter-temporal dimension of the relation between the two phenomena. In this respect, the data from the National Longitudinal Surveys (NLS) provide a great amount of relevant information. Out of the set of all the available NLS three datasets will be taken into considerations: The NLS of Mature Women (NLSMW), the NLS of Young Women (NLSYW) and the NLS of Youth 1979 (NLSY79) ${ }^{17}$. The first two share a very similar structure, allowing for a relevant degree of comparability. In the NLSMW around 5,000 women are first interviewed in 1967 when aged between 30-44 and then are reinterviewed at irregular time intervals until 2007. In total I can count on 16 waves. Taking into consideration the fact that only women which got married (at least once) are at risk of divorce, I drop from the sample all the individuals who never married. The data suffer from a considerable degree of attrition due to a number of effects (death, poor quality of some interviews, impossibility to constantly locate the individual, etc.). In all, the used sample starts with 4,615 individuals and includes 52,892 observations. The questions cover a multiplicity of fields and tend to vary in different years. Nonetheless, in each wave a consistent bulk of questions regarding the demographic, social and economic characteristics of the individual can be found, making the exploitation of the panel dimension of the dataset absolutely feasible.

\footnotetext{
${ }^{17}$ Full details about all these datasets are available on the web page: http://www.bls.gov/nls/.
} 
The National Longitudinal Survey of Young Women (NLSYW) can be seen as a "twin dataset" with respect to the NLSW. Both the set of questions posed and the sampling strategy are in fact extremely similar to those described above. The interviews started in 1968 and the last one took place in 2003. The sampled individuals in this case are representative of different cohorts with respect to the respondents of the NLSMW, for their age being included between 15 and 24 years when first interviewed in 1968. By reducing the sample to all the individuals that have experienced marriage, I can make use of information on 4,316 women, with a total of 52,987 observations.

The National Longitudinal Survey of Youth (NLSY79) substantially differs from the previous datasets. In this case in fact, the analysis is conducted on a sample of 13,201 individuals, including both women $(7,006)$ and men $(6,195)$. The interviews were first conducted in 1979, and the respondents were interviewed annually through 1994 and are currently interviewed on a biennial basis. Given the young age of the individuals included in this dataset, the attrition in this case represents a less problematic phenomenon. Nonetheless, due the fact that the focus is on respondents that have been married at least once, the number of observations is relatively small. The total number of observations is 92,513 . With the inclusion of these data I am able to collect a relevant set of variables on several cohorts, ideally covering the whole spell of time between 1967 and 2003. Tables 12 and 13 in Appendix 1 provide some descriptive statistics with respect to the variables included in all the NLS samples under investigation in this paper.

\subsection{Time Use Data}

As already suggested in the introduction, the simultaneous occurrence of a number of social and economic changes that have led to an relevant increase in the female labour supply and the male participation in household activities might have directly affected the amount and the quality of

the time spouses spend together. The second part of the present study aims at the analysis of the extent of these changes and to their relation with the pattern of divorce rate in the US. The extent of "togetherness" within American household, its inter-temporal dynamics and its relations with the way partners spend their time is studied in this paper making use of data from three waves of the American Time Use datasets. Due to the increased availability of these datasets and the improved quality level of provided information, working with diary surveys has become a widely popular choice among applied researchers in the last few years. The already cited article by Aguiar 
and Hurst (2007), which focuses on the determinants of the increase in leisure time of Americans in the last forty years, probably represents the most cited example within this strand of literature. A number studies have focused on other phenomena related to family economics. With no presumption of completeness, it is worth to mention the contributions of Ramey (2008) on the changes of home production patterns across time, Guryan, Hurst, and Kearney (2008) on the impact of education on the time spent by parents with their children and Datta Gupta and Stratton (2008) (using both American and Danish data) on the relations between changes in leisure time and bargaining power within the couple ${ }^{18}$.

The dataset I use is based on surveys of the American Time Use Data as harmonized by the American Heritage Time Use Study ${ }^{19}$. The data are collected from the 1965-1966 Multinational Comparative Time-Budget Research Project, the 1975-1976 American's Use of Time and the 2003 American Time Use Survey ${ }^{20}$. Evidently, the sources of information are different, but all the datasets are characterized by a considerable degree of homogeneity in almost all the relevant variables. For instance, the time use variables are rather consistently categorized across surveys. Each individual is asked to indicate the amount of minutes she spends in every activity she carries out during the day ${ }^{21}$. The total amount of minutes indicated by every person is equal to 1440 , so that the whole day is covered. The number of activities which can be chosen varies a little across surveys, from a minimum of 85 up to 94 . I have initially grouped these variables into 13 categories, summarizing the main activities: work, education, household chores, purchases, childcare, adult care, voluntary activities, leisure, sport, social activities, art, relaxation (including sleep), travel (not toward work place $)^{22}$. Furthermore, in these surveys the interviewed individuals are also requested to specify the amount of time they spend alone, with their partner and with other people. These last variables represent an important tool in order to disentangle the differences in the way couples have changed their time consumption patterns across the last four decades. Table 2 shows some descriptive statistics of the data. In total, the sample I use for my analysis is composed of 247,117

\footnotetext{
${ }^{18}$ As an example of a time use analysis not directly linked to family economics, see Aguiar and Hurst (2008). For a theoretical approach to the relation between time allocated in home production and market work and divorce and marital rates see Greenwood and Guner (2004).

${ }^{19}$ For more details on the data and the harmonization procedures, see http://www.timeuse.org/ahtus/

${ }^{20}$ The American Heritage Time Use Study also includes waves from 1985 and 1993. Nonetheless, these waves can not be included in my analysis as they lack two extremely relevant variables: in the 1985 survey does not include any information on the time each individual spends with her partner, while in the 1993 dataset the sampled individuals are not required to provide any details regarding their marital status.

${ }^{21}$ Each individual is asked to indicate a main activity and a potential secondary activity she might carry out together with the main one. In my analysis I will concentrate on main activities only.

${ }^{22}$ The average times spent in each activity in different decades are reported in table 18 and tabel 19 in the Appendix.
} 


\begin{tabular}{lccc}
\hline \hline & Total & Male & Females \\
\hline Observations & 247,117 & $41.39 \%$ & $58.61 \%$ \\
& & & \\
Average Age & 40.77 & 41.91 & 39.97 \\
& 10.75 & 10.78 & 10.66 \\
& & & \\
Race White & $90.61 \%$ & $89.38 \%$ & $91.48 \%$ \\
Others & $9.39 \%$ & $10.62 \%$ & $8.52 \%$ \\
& & & \\
With Children & $67.00 \%$ & $66.33 \%$ & $68.70 \%$ \\
& & & \\
Low Education & $13.17 \%$ & $14.53 \%$ & $12.06 \%$ \\
High School & $34.17 \%$ & $30.12 \%$ & $37.03 \%$ \\
College & $52.66 \%$ & $55.35 \%$ & $50.91 \%$ \\
& & & \\
Employed & $74.07 \%$ & $93.95 \%$ & $60.04 \%$ \\
& & & \\
1st Income Quart. & $8.84 \%$ & $8.61 \%$ & $9.00 \%$ \\
4th Income Quart. & $39.69 \%$ & $41.58 \%$ & $38.35 \%$ \\
\hline \hline
\end{tabular}

Table 2: Sample Descriptive Statistics

married individuals, $58.61 \%$ of which are women, aged 21 to 65 . The survey which contributes the most is the one of 2003, in which 177,000 individuals are included.

\section{Household Responsibilities and Probability to Divorce}

The simple descriptive statistics presented in section 1 suggest an increase in the male involvement in the management of household activities in terms of the amount of time devoted to household activities in the last five decades. At the same time, the patterns of household time consumption of women present a non-monotonic trend with respect to childcare and a clear decrease in time devoted to household chores. These results can effectively linked to the individual probability of divorce of American couples via the described NLS data. In these surveys, in fact, all the sampled populations are asked to provide information on the way they share some of the household responsibilities with the other members of the family. By using the resulting variables as proxies for home activities in general and including them in the set of regressors used to study the probability of divorce, I investigate how different attitudes toward home activities may be correlated to the stability of a marriage. In this way, the likelihood of survival of the marital relationship is directly related to 
the marriage-specific investment since not only the amount of time dedicated to a certain activity matters, but the kind of performed activity is by itself crucial for the duration of a relationship.

The empirical strategy employed in this section is that of a standard survival analysis on discretely grouped data (but with a continuous underlying survival process), performed through a complementary log-log specification ${ }^{23}$, in which the dependent variable is given by the hazard rate of divorce. The starting point is given by the following survivor function at time $a_{j}$ :

$$
S\left(a_{j}, X\right)=\exp \left[-\int_{0}^{a_{j}} \theta(u, X) d u\right]
$$

where the the survivor function $S\left(a_{j}, X\right)$ (in this case indicating the probability of remaining married at least $a_{j}$ periods of time) is linked to the realizations of a set of variables $X$ directly linked to the underline continuous hazard process in the following way: $\theta(t, X)=\theta_{0}(t) e^{\beta^{\prime} X}$. Defining the discrete time hazard function as:

$$
h_{j}=\frac{S\left(a_{j-1}, X\right)-S\left(a_{j}, X\right)}{S\left(a_{j-1}, X\right)}
$$

and taking into account eq.(1):

$$
h_{j}=1-\exp \left[e^{\beta^{\prime} X}\left(\Omega_{j-1}-\Omega_{j}\right)\right]
$$

is obtained, where $\Omega_{j}=\int_{0}^{a_{j}} \theta_{0}(u, X) d u$.

This eventually leads to:

$$
h\left(a_{j}, X\right)=1-\exp \left[-\exp \left(\beta^{\prime} X+\gamma_{j}\right)\right]
$$

where $\gamma_{j}=\log \left[\int_{a_{j-1}}^{a_{j}} \theta_{0}(u) d u\right]$. This is the final expression for the equation which, given a set of covariates $X$, can be estimated ${ }^{24}$. Furthermore the last equation can be modified in order to account for unobserved heterogeneity. Taking the logarithms of (4) and adding an error term $v$ we can obtain:

\footnotetext{
${ }^{23}$ For a good theoretical introduction to survival analysis see Jenkins (2005) and Wooldridge (2001), chapter 20. Hosmer, Lemeshow, and May (2008) provide a good summary of applied techniques for survival analysis.

${ }^{24}$ The estimation procedures have also been repeated using a logit specification, obtaining results which are very similar to those presented.
} 


$$
\operatorname{clog} \log \left[h\left(a_{j}, X \mid v\right)\right]=\Omega_{j}+\beta^{\prime} X+u
$$

where $u=\log (v)$. The possibility to further manipulate (5) in order to obtain the corresponding survival function depends on the assumption on the functional form of $u$. In what follows I will assume that $u$ follows a zero-mean Normal distribution and the results of the estimation obtained taking into account unobserved heterogeneity will be presented along those where this phenomenon is not accounted for ${ }^{25}$.

The estimation procedure is then rather simple ${ }^{26}$. Each individual is followed for the entire duration of her marriage. For each dataset I run a regression in which the dependent variable is a dummy which takes value 0 in every period the individual is married; if the individual divorces the dummy takes value 1 in the first year of divorce and the individual is then dropped from the sample (and possibly included again in case of new marriage). The dependent variable is regressed against a set of independent ones which contain the log of the length of the "treatment period" (i.e. the marriage), several personal and demographic characteristics and the set of dummy variables on the responsibility of household chores. This last set of variables varies depending on the dataset taken into consideration. The NLSMW and the NLSYW are characterized by a relevant degree of homogeneity, so that the results obtained by the described regression on the two datasets can be easily compared. The set of household responsibilities included in my regressions is composed by: grocery shopping, childcare, cooking, cleaning the dishes, housekeeping, washing the clothes and garden maintenance. The questions related to this topic are designed in a way that allows to identify the person within the family which is mainly (but not necessarily the only) responsible for the chore (which might be not only one of the spouses but also a third person). It then become possible to study the probability of divorce as function of the way chores are split between partners ${ }^{27}$. Such an analysis gains momentum as it is performed on two different cohorts of individuals interviewed in the same period, so that it is possible to control for the emergence of different attitudes toward these responsibilities. Table 3 shows some descriptive statics related to the variables of interest.

\footnotetext{
${ }^{25}$ An alternative specification would consist in assuming that the error term follows a Gamma distributions (see Abbring and Berg (2007)). The results obtained with such a specification are very similar to those obtained assuming a Normal distribution and therefore are not presented.

${ }^{26}$ Details on how to perform the estimation of the suggested equations can be found in Jenkins (1995) and Jenkins (1998).

${ }^{27}$ For each variable I construct two dummies, one for the respondent and one for her husband, that take value 1 if the respondent or the husband are the responsible persons for the chore. The dummy variables are then included in set of regressors.
} 


\begin{tabular}{|c|c|c|c|c|c|c|}
\hline & \multicolumn{3}{|c|}{ NLSW } & \multicolumn{3}{|c|}{ NLSY } \\
\hline & Wife & Husband & $\begin{array}{l}\text { Number of } \\
\text { Observations }\end{array}$ & Wife & Husband & $\begin{array}{c}\text { Number of } \\
\text { Observations }\end{array}$ \\
\hline Grocery Shopping & 61.10 & 26.31 & 49,058 & 68.32 & 28.87 & 45,584 \\
\hline Childcare & 44.75 & 14.39 & 32,177 & 39.18 & 52.07 & 40,616 \\
\hline Cooking & 70.63 & 14.25 & 48,873 & 70.62 & 22.80 & 45,543 \\
\hline Cleaning Dishes & 53.54 & 18.57 & 48,864 & 52.53 & 22.88 & 45,501 \\
\hline House Keeping & 57.64 & 14.40 & 48,861 & 57.06 & 23.34 & 45,548 \\
\hline Washing Clothes & 74.79 & 7.38 & 48,874 & 77.97 & 13.02 & 45,563 \\
\hline Yard Maintenance & 9.73 & 58.19 & 47,699 & 13.00 & 67.41 & 43,087 \\
\hline
\end{tabular}

Table 3: Percentage of positive answers

The figures present the percentage of women that indicated themselves or their husbands as the person responsible for a certain chore in the household. The simple observation of the table suggests a clear division between chores whose responsibility mostly pertains to women and those mostly performed by men (that in the set of available variables are represented by "yard maintenance"). It is worth noticing some differences in the percentages we observe with respect to the two datasets. In particular, the percentage of husbands which are (at least partly) responsible for the chores is systematically higher in the NLSYW than in the NLSMW and this regularity applies to all the household activities included in the analysis. Furthermore, with the notable exception of childcare, for which the role of men appears to have gained an extremely relevant impact, the percentage related to women have not changed in very significant way. This fact suggests that for younger cohorts a more active role of men in the management of the household can be highlighted, possibly as a substitute for the work of third persons.

The study conducted on the NLSY79 dataset is slightly different, as the questions only ask whether the respondent is responsible for the chores (the list of activities is extremely similar to the one of the NLSMW and NLSYW). It is therefore not possible to identify the person responsible for the chore, were the respondent not in charge. In particular, the questions ask the respondent to indicate how often he or she takes care of a particular household activity. Table 4 shows the percentages of individuals which have indicated one answer among: "Half of the time", "Most of the times", "Always". Due to the differences in the formulation of the questions a direct comparison of the figures presented in tables 3 and 4 would not be appropriate. Nonetheless it can certainly be noticed that the division of tasks between genders is once more evident. The fact that the 


\begin{tabular}{lcc|cc}
\hline \hline & Wife & $\begin{array}{c}\text { Number of } \\
\text { Observations }\end{array}$ & Husband & $\begin{array}{c}\text { Number of } \\
\text { Observations }\end{array}$ \\
\hline Childcare & 95.40 & 10,079 & 37.29 & 4,248 \\
Cooking & 87.73 & 16,269 & 12.60 & 8,317 \\
Cleaning Dishes & 89.87 & 16,269 & 13.61 & 8,317 \\
Errands & 67.53 & 16,235 & 56.97 & 8,301 \\
Grocery Shopping & 85.42 & 16,232 & 40.38 & 8,316 \\
House Keeping & 91.95 & 16,269 & 16.58 & 8,298 \\
Washing Clothes & 90.21 & 16,259 & 13.23 & 8,317 \\
House Maintenance & 24.33 & 16,269 & 74.37 & 8,317 \\
Outdoor Chores & 29.71 & 16,250 & 63.00 & 8,301 \\
Paperwork & 62.21 & 16,247 & 46.85 & 8,303 \\
\hline \hline \multicolumn{2}{l}{ Question: "Are you the one responsible for the chore?" }
\end{tabular}

Table 4: Percentage of Individuals Answering: "Half of the Time and More"

list of activities is slightly richer comparing to those of NLSWM and NLSYW allows for a better identification of the chores that can be seen as mostly "male-oriented". In particular we can refer to the percentages that characterize "outdoor chores", "house maintenance" and (to some extent) "errands" as examples of this types of activities.

Table 5 reports the results of the empirical analysis on the NLSMW and NLSYW with respect to the household chores included in the set of regressors and a few other relevant variables (the complete regressions and a description of the variables are presented in Appendix 2). For each dataset column (1) shows the results obtained without taking unobserved heterogeneity into account, while column (2) presents the results observed when the specification suggested by (5) is followed. All the coefficients are presented in form of hazard ratios, so that each figure can be interpreted as the proportional effect induced on the hazard of divorce by a change in the regressor. The way to interpret hazard ratios when controlling for unobserved heterogeneity in the context of proportional hazard models has being extensively analyzed by Hougaard (1986). The fact that a Normal distribution is assumed for the error term guarantees the validity of the interpretation of the coefficients at any time $t$ different from the initial period of observation ${ }^{28}$. The corresponding results in terms of hazard rate can be found in tables 14 and 15 in Appendix 2. As the results do not vary significantly across columns any comment will be based on the results presented in column (1), but can of course be easily applied to column (2). As the average duration of a marriage for the Mature Women is above 20 years, while it does not reach 7 years for the individuals included in

\footnotetext{
${ }^{28}$ See also Gutierrez (2002).
} 
the Young Women sample, the differences in the effects of the duration of marriage in the samples is to be linked to a cohort effect. This is in line with what has already been found in the relevant literature ${ }^{29}$ and any conclusions to be drawn with respect to this dataset should always take this difference into consideration. Hence, it is quite surprising to observe that the impact of remarriage is particularly important with respect to young women. Of course, in the NLSYW sample the number of respondents that have already experienced more than one marriage is relatively limited (less than 1,000 individuals out of 5,200), so that the estimated coefficient appears extremely relevant. To some extent, the parameter suggests that the attitude toward marriage per se can play an important role in the stability of a partnership ${ }^{30}$, so that if a woman has experienced a divorce in the first marriage, the likelihood of divorce in case she remarries is higher compared to the hazard for those that have never experienced a divorce.

Focusing more on the effect of the responsibility of the household chores, some regularities in the estimated parameters deserve to be highlighted. All coefficients are to be interpreted in relation to the excluded category, which is that of individuals other than wife or husband being responsible for the chore. In both samples the majority of the statistically significant parameters point in the direction of a negative effect (indicated by a coefficient between 0 and 1) and are linked to activities performed by the husband. The results related to the NLSMW samples up to three activities are connected to a reduction in the hazard of divorce when (at least partly) performed by the husband, namely grocery shopping, hose cleaning and childcare. The latter is the only variable that still presents a negative and statistically significant relation in the study conducted on the NLSYW data. Linking this evidence to what observed in section 1 and in particular to the fact that the average time men spend on childcare and household chores is increasing over time and assuming a (perhaps stereotypical) point of view in which the woman is traditionally responsible for housekeeping activities and the man takes care of the garden and the outdoor $\operatorname{tasks}^{31}$, the estimated parameters suggest that moving away from this framework, implying a more relevant participation of the men in the household activities, positively relates to the duration of a marriage but such a result does not appear to be robust in a long run perspective. A different evidence characterizes the pattern of the coefficients related to "yard maintenance", the only "male

\footnotetext{
${ }^{29}$ See, for example, Weiss and Willis (1997).

${ }^{30}$ Although within a different context, some of the findings of Lillard, Brien, and Waite (1995) confirm this hypothesis.

${ }^{31}$ Some hints about the validity of this point of view can be found in Becker (1973), Akerlof and Kranton (2000) and Cherlin (2004).
} 


\begin{tabular}{|c|c|c|c|c|}
\hline \multirow{3}{*}{ Duration of Marriage } & \multicolumn{2}{|c|}{ NLSMW } & \multicolumn{2}{|c|}{ NLSYW } \\
\hline & (1) & (2) & (1) & $(2)$ \\
\hline & $\begin{array}{l}0.590^{* * *} \\
(-2.64)\end{array}$ & $\begin{array}{l}0.592^{* *} \\
(3.88)\end{array}$ & $\begin{array}{l}1.665^{* * *} \\
(-2.51)\end{array}$ & $\begin{array}{l}2.436^{* * *} \\
(4.47)\end{array}$ \\
\hline Number of Marriage & $\begin{array}{l}1.447 \\
(1.44)\end{array}$ & $\begin{array}{l}1.559 \\
(4.22)\end{array}$ & $\begin{array}{l}1.807^{* * *} \\
(1.40)\end{array}$ & $\begin{array}{l}2.298^{* * *} \\
(4.15)\end{array}$ \\
\hline Age & $\begin{array}{l}1.483^{* * *} \\
(4.48)\end{array}$ & $\begin{array}{l}1.490^{* * *} \\
(10.77)\end{array}$ & $\begin{array}{l}1.964^{* * *} \\
(4.43)\end{array}$ & $\begin{array}{l}2.127^{* * *} \\
(10.18)\end{array}$ \\
\hline $\mathrm{Age}^{2}$ & $\begin{array}{l}0.997^{* * *} \\
(-4.14)\end{array}$ & $\begin{array}{l}0.997^{* * *} \\
(-10.03)\end{array}$ & $\begin{array}{l}0.992^{* * *} \\
(-4.12)\end{array}$ & $\begin{array}{l}0.991^{* * *} \\
(-9.60)\end{array}$ \\
\hline Grocery Wife & $\begin{array}{l}0.786 \\
(-1.19)\end{array}$ & $\begin{array}{l}0.780 \\
(-1.21)\end{array}$ & $\begin{array}{l}0.792 \\
(-1.55)\end{array}$ & $\begin{array}{l}0.778 \\
(-1.33)\end{array}$ \\
\hline Grocery Husband & $\begin{array}{l}0.255^{* * *} \\
(-3.72)\end{array}$ & $\begin{array}{l}0.251^{* * *} \\
(-3.72)\end{array}$ & $\begin{array}{l}0.781 \\
(-1.47)\end{array}$ & $\begin{array}{l}0.759 \\
(-1.34)\end{array}$ \\
\hline Childcare Wife & $\begin{array}{l}1.111 \\
(0.67)\end{array}$ & $\begin{array}{l}1.118 \\
(0.69)\end{array}$ & $\begin{array}{l}1.085 \\
(0.69)\end{array}$ & $\begin{array}{l}1.069 \\
(0.44)\end{array}$ \\
\hline Childcare Husband & $\begin{array}{l}0.525^{* *} \\
(-1.97)\end{array}$ & $\begin{array}{l}0.523^{* *} \\
(-1.96)\end{array}$ & $\begin{array}{l}0.627^{* * *} \\
(-3.54)\end{array}$ & $\begin{array}{l}0.546^{* * *} \\
(-3.62)\end{array}$ \\
\hline Cooking Wife & $\begin{array}{l}0.953 \\
(-0.22)\end{array}$ & $\begin{array}{l}0.952 \\
(-0.22)\end{array}$ & $\begin{array}{l}1.052 \\
(0.36)\end{array}$ & $\begin{array}{l}1.035 \\
(0.20)\end{array}$ \\
\hline Cooking Husband & $\begin{array}{l}0.688 \\
(-0.88)\end{array}$ & $\begin{array}{l}0.680 \\
(-0.90)\end{array}$ & $\begin{array}{l}1.036 \\
(0.22)\end{array}$ & $\begin{array}{l}1.034 \\
(0.17)\end{array}$ \\
\hline Dishes Wife & $\begin{array}{l}1.119 \\
(0.51)\end{array}$ & $\begin{array}{l}1.113 \\
(0.48)\end{array}$ & $\begin{array}{l}0.870 \\
(-1.17)\end{array}$ & $\begin{array}{l}0.842 \\
(-1.15)\end{array}$ \\
\hline Dishes Husband & $\begin{array}{l}0.873 \\
(-0.36)\end{array}$ & $\begin{array}{l}0.875 \\
(-0.35)\end{array}$ & $\begin{array}{l}0.909 \\
(-0.61)\end{array}$ & $\begin{array}{l}0.856 \\
(-0.81)\end{array}$ \\
\hline House Keep. Wife & $\begin{array}{l}0.816 \\
(-0.88)\end{array}$ & $\begin{array}{l}0.816 \\
(-0.87)\end{array}$ & $\begin{array}{l}0.947 \\
(-0.42)\end{array}$ & $\begin{array}{l}0.912 \\
(-0.56)\end{array}$ \\
\hline House Keep. Husband & $\begin{array}{l}0.305^{* *} \\
(-2.08)\end{array}$ & $\begin{array}{l}0.301^{* *} \\
(-2.08)\end{array}$ & $\begin{array}{l}1.078 \\
(0.46)\end{array}$ & $\begin{array}{l}1.049 \\
(0.24)\end{array}$ \\
\hline Clothes Wife & $\begin{array}{l}0.714 \\
(-1.55)\end{array}$ & $\begin{array}{l}0.711 \\
(-1.54)\end{array}$ & $\begin{array}{l}0.783^{*} \\
(-1.80)\end{array}$ & $\begin{array}{l}0.691^{* *} \\
(-2.11)\end{array}$ \\
\hline Clothes Husband & $\begin{array}{l}1.166 \\
(0.30)\end{array}$ & $\begin{array}{l}1.176 \\
(0.32)\end{array}$ & $\begin{array}{l}0.783 \\
(-1.28)\end{array}$ & $\begin{array}{l}0.754 \\
(-1.19)\end{array}$ \\
\hline Gardening Wife & $\begin{array}{l}1.227 \\
(1.03)\end{array}$ & $\begin{array}{l}1.253 \\
(1.10)\end{array}$ & $\begin{array}{l}1.600^{* * *} \\
(3.70)\end{array}$ & $\begin{array}{l}1.887^{* * *} \\
(3.75)\end{array}$ \\
\hline Gardening Husband & $\begin{array}{l}0.180^{* * *} \\
(-7.96)\end{array}$ & $\begin{array}{l}0.179^{* * *} \\
(-7.89)\end{array}$ & $\begin{array}{l}0.670^{* * *} \\
(-3.47)\end{array}$ & $\begin{array}{l}0.584^{* * *} \\
(-3.65)\end{array}$ \\
\hline Log lik. & -995.1 & -994.9 & -2177.8 & -2165.3 \\
\hline Chi-2 & 377.2 & 234.0 & 924.9 & 359.7 \\
\hline Observations & 25537 & 25537 & 22671 & 22671 \\
\hline
\end{tabular}

Dependent Variable: Marital Status, $0=$ Married, $1=$ Divorce

Table 5: Clog-log analysis 
dominated" activity included in the samples under investigation. With respect to the sample of the Mature Women, the parameters related to this chore suggest that the performance of these tasks by the husband is negatively correlated to the likelihood of divorce and this result is confirmed in the analysis conducted on the Young Women sample. But with respect to this last dataset, we can certainly notice how the parameter characterizing this variable when performed by the wife appears to be larger than 1 (and statistically significant), suggesting an increase in the risk of divorce of a magnitude of $60 \%$, coeteris paribus. The coefficients indicate the existence of a relevant rigidity in the way the division of tasks relates to the hazards of divorce, with particular reference to the possibility for men to delegate the "male chores" to women. This result can not be considered surprising: The analysis on the Time Use Data has already highlighted a considerable reduction in the time women tend to devote to household chores in favour of an increase in time dedicated to leisure activities. The scope for a substitution of female time for that of men in the performance of chores such as the maintenance of yard is therefore extremely limited, especially with respect to younger cohorts.

The estimated regularities presented in table 5 are confirmed by the figures shown in table 6 , which summarizes the results of the regressions performed on the data available through the National Longitudinal Survey of Youth 1979 (the whole set of results can be found in tables 16 and 17$)^{32}$. In this case the variables related to household chores are recorded as dummies taking value one if the respondent is in charge for the chore, zero otherwise. If we focus on the subset of variables composed by "errands", "outdoor chores" and "house maintenance", it is easy to notice that the relation of these regressors with the hazard of divorce follow the same patterns previously highlighted with respect to "yard maintenance". The possibility that the wife is (at least half of the time) the person in charge for carrying out these chores implies an increase in the hazard of divorce, validating the hypothesis of a limited substitutability of partner times on predominantly male activities. Furthermore, it is interesting to notice that the link between of the participation of men in household activities on the likelihood of divorce does not appear to be very relevant (the only exception being the coefficient related to "outdoor activities", which goes in the direction already outlined with respect to the set of "man activities"). The estimates in this sense confirm the pattern already outlined with respect to the differences between the results obtained with the

\footnotetext{
${ }^{32}$ Again, column (1) shows the results when heterogeneity is not taken into account, while column (2) presents the coefficient obtained when correcting for heterogeneity. Given the evident similarity of the two sets of results only the results obtained in the corresponding column (1) are reported in the Appendix.
} 


\begin{tabular}{|c|c|c|c|c|}
\hline \multirow[t]{2}{*}{ NLSY79 } & \multicolumn{2}{|c|}{ Men } & \multicolumn{2}{|c|}{ Women } \\
\hline & (1) & (2) & (1) & $(2)$ \\
\hline Duration of Marriage & $0.545^{* * *}$ & $0.545^{* * *}$ & $0.476^{* * *}$ & $0.426^{* * *}$ \\
\hline & & $(-2.10)$ & $10.00)$ & $(-4.79)$ \\
\hline Number of Marriages & $\begin{array}{l}1.238 \\
(0.46)\end{array}$ & $\begin{array}{l}1.237 \\
(0.46)\end{array}$ & $\begin{array}{l}1.287 \\
(1.29)\end{array}$ & $\begin{array}{l}1.305 \\
(1.13)\end{array}$ \\
\hline Age & $\begin{array}{l}2.267^{* * *} \\
(4.60)\end{array}$ & $\begin{array}{l}2.276^{* * *} \\
(4.40)\end{array}$ & $\begin{array}{l}1.315^{* * *} \\
(2.80)\end{array}$ & $\begin{array}{l}1.480^{* * *} \\
(3.07)\end{array}$ \\
\hline $\mathrm{Age}^{2}$ & $\begin{array}{l}0.988^{* * *} \\
(-4.69)\end{array}$ & $\begin{array}{l}0.988^{* * *} \\
(-4.53)\end{array}$ & $\begin{array}{l}0.997^{* *} \\
(-2.34)\end{array}$ & $\begin{array}{l}0.995^{* * *} \\
(-2.69)\end{array}$ \\
\hline Resp. Childcare & $\begin{array}{l}1.004 \\
(0.02)\end{array}$ & $\begin{array}{l}1.004 \\
(0.02)\end{array}$ & $\begin{array}{l}0.896 \\
(-0.44)\end{array}$ & $\begin{array}{l}0.976 \\
(-0.08)\end{array}$ \\
\hline Resp. Cooking & $\begin{array}{l}1.017 \\
(0.04)\end{array}$ & $\begin{array}{l}1.019 \\
(0.05)\end{array}$ & $\begin{array}{l}0.503^{\text {*** }} \\
(-3.42)\end{array}$ & $\begin{array}{l}0.449^{* * *} \\
(-3.07)\end{array}$ \\
\hline Resp. Dishes & $\begin{array}{l}1.529 \\
(1.17)\end{array}$ & $\begin{array}{l}1.525 \\
(1.15)\end{array}$ & $\begin{array}{l}1.014 \\
(0.06)\end{array}$ & $\begin{array}{l}1.054 \\
(0.19)\end{array}$ \\
\hline Resp. Grocery Shopping & $\begin{array}{l}0.846 \\
(-0.67)\end{array}$ & $\begin{array}{l}0.846 \\
(-0.67)\end{array}$ & $\begin{array}{l}0.752 \\
(-1.45)\end{array}$ & $\begin{array}{l}0.692 \\
(-1.54)\end{array}$ \\
\hline Resp. Housekeeping & $\begin{array}{l}0.850 \\
(-0.52)\end{array}$ & $\begin{array}{l}0.852 \\
(-0.51)\end{array}$ & $\begin{array}{l}1.569^{*} \\
(1.72)\end{array}$ & $\begin{array}{l}1.503 \\
(1.29)\end{array}$ \\
\hline Resp. Washing Clothes & $\begin{array}{l}0.772 \\
(-0.51)\end{array}$ & $\begin{array}{l}0.769 \\
(-0.52)\end{array}$ & $\begin{array}{l}0.885 \\
(-0.55)\end{array}$ & $\begin{array}{l}0.840 \\
(-0.64)\end{array}$ \\
\hline Resp. Errands & $\begin{array}{l}1.098 \\
(0.45)\end{array}$ & $\begin{array}{l}1.096 \\
(0.43)\end{array}$ & $\begin{array}{l}1.593^{* * *} \\
(3.26)\end{array}$ & $\begin{array}{l}1.718^{* * *} \\
(3.14)\end{array}$ \\
\hline Resp. House Maintenance & $\begin{array}{l}0.981 \\
(-0.08)\end{array}$ & $\begin{array}{l}0.980 \\
(-0.08)\end{array}$ & $\begin{array}{l}1.321^{* *} \\
(2.15)\end{array}$ & $\begin{array}{l}1.467^{* *} \\
(2.36)\end{array}$ \\
\hline Resp. Outdoor Chores & $\begin{array}{l}0.518^{* * *} \\
(-2.67)\end{array}$ & $\begin{array}{l}0.517^{* * *} \\
(-2.65)\end{array}$ & $\begin{array}{l}1.047 \\
(0.35)\end{array}$ & $\begin{array}{l}1.025 \\
(0.15)\end{array}$ \\
\hline Resp. Paperwork & $\begin{array}{l}1.831^{* * *} \\
(2.53)\end{array}$ & $\begin{array}{l}1.826^{* *} \\
(2.47)\end{array}$ & $\begin{array}{l}1.083 \\
(0.58)\end{array}$ & $\begin{array}{l}1.068 \\
(0.40)\end{array}$ \\
\hline Log lik. & -354.3 & -354.3 & -1057.6 & -1054.8 \\
\hline Chi-2 & 332.2 & 199.9 & 389.7 & 258.6 \\
\hline Observations & 3019 & 3019 & 5522 & 5522 \\
\hline
\end{tabular}

Dependent Variable: Marital Status, $0=$ Married, $1=$ Divorce

Table 6: Clog-log analysis 
NLSMW and the NLSYW data and they can be interpreted as reflecting a different perception of men's role within the household: Over the last four decades the involvement of men in house activities has evolved from an exceptional event to a common practice so that no actual impact of these activities on the duration of a relationship can be detected ${ }^{33}$.

The picture obtained from the estimates shown in tables 5 and 6 can be considered to some extent surprising if related to the time trends in partners involvement in household activities as presented in tables 1, 3 and 4. As the male participation in the chores in terms of minutes per day considerably increases over time the empirical linkage between the participation and its marginal contribution to the stability of the marital union loses momentum across cohorts. It is certainly possible to connect these findings to the historical trends in the American divorce rate. It is known that this rate (either calculated as the number of divorces per thousand of married individuals or simply as the number of divorce per thousand of individuals) has been decreasing in the last twenty years, somehow differentiating the US experience from that of all the other developed countries ${ }^{34}$. The estimates obtained with respect to the NLSMW sample suggest that a more balanced intrahousehold division of tasks can be considered one of the elements that might have substantially contributed to the inversion in the trend of divorces, from increasing to decreasing, that can be observed from 1982 onward. With respect to more recent cohorts, as seen, the relation between marriage success and male involvement in female dominated tasks is not particularly strong, but the decrease in the divorce rate still characterizes the American marital market. It appears therefore natural to argue for the possibility to introduce a new dimension in the analysis of the patterns of allocation of time and responsibilities within families. In particular, in the next section I will try to investigate whether other changes beyond the simple division of chores might have occurred in U.S. households over the last four decades. As has already been pointed out by Aguiar and Hurst (2007), the amount of time Americans devote to leisure activities has consistently increased over this temporal horizon. This fact bears as a consequence the possibility to investigate whether couples' decision to spend time together is nowadays more likely to depend on the availability of

\footnotetext{
${ }^{33}$ The estimates presented in tables 5 and 6 are based on the analysis of samples characterized by a relative high number of observations. This fact can be taken into consideration when evaluating the significance level of the coefficients, making use of the formula developed by Leamer (1978), ch.14. The suggested statistic is given by $F>\frac{T-k}{p} \times\left(T^{p / T}-1\right)$, where $T$ is the number of observations, $T-k$ the degrees of freedom and $p$ summarizes the number of restrictions. Even after having obtained the critical thresholds according to this method, most of the statistically significant parameters can be considered valid, with the only possible exception of "Childcare Husband" for NLSMW.

${ }^{34}$ Stevenson and Wolfers (2007) provide a relevant amount of data for the study of the decrease in the American divorce rate
} 


\begin{tabular}{lcclc}
\hline \hline & $\mathbf{1 9 6 5}$ & $\mathbf{1 9 7 5}$ & $\mathbf{2 0 0 3}$ & Diff.03-65 \\
\hline Males & & & & \\
Leisure & 19.4219 & 19.0704 & 32.1297 & 12.708 \\
House Chores & 41.9492 & 65.3166 & 75.7055 & 33.756 \\
Childcare & 16.6116 & 17.843 & 46.4042 & 29.793 \\
Time with Spouse & 244.116 & 345.704 & 317.049 & 72.933 \\
\hline Females & & & & \\
Leisure & 18.8104 & 15.3027 & 33.0473 & 14.237 \\
House Chores & 266.105 & 190.778 & 149.539 & 116.566 \\
Childcare & 72.900 & 56.2074 & 94.884 & 21.984 \\
Time with Spouse & 235.252 & 334.57 & 289.928 & 54.676 \\
\hline All differences presented in the last column are statistically significant at 1\% level. \\
\multicolumn{5}{c}{ Table 7: Average Time per Day (in Minutes) }
\end{tabular}

quality time, here represented by leisure, comparing to the last forty years.

\section{The Results on Time Consumption}

The starting point for the empirical analysis of the relation between time at home and the extent of quality time consumed by partners consists in the identification of the across decades correlation patterns between the amount of time partners spend together, identified by the variable "Time Spent with Spouse" (TWS), and a set of relevant time use variables. More specifically, I link TWS to a bundle of time consuming activities and see whether changes in the composition of this bundle might have an influence on the way individuals shape their time with the partners. As including all the thirteen time use categories described in section 3.2 into my empirical study would of course lead to relevant problems in terms of multicollinearity and endogeneity of the time allocation choice, I limit the number of activities to be included in the set of regressors to three: Household chores, childcare and leisure. Although a certain degree of arbitrariness can not be avoided when implementing this kind of selection, the three variables appear to be particularly relevant for the present analysis. The importance of the first two has already been assessed with respect to the relation between their inter-temporal management of across families and the likelihood of divorce. A substantive modification over time on the way these activities relate to the amount of time each individual spends with her/his spouse could represent a good indicator of changes in the way couples shape their time together. The relevance of the time spent in "leisure" on explaining the amount of time partners spend together is to be related to the attempt of linking TWS with the increased 
importance achieved by time use complementarities within the couple. For instance, leisure is to be seen as a proxy for all those activity that people may perform in order to relax and amuse themselves. In this respect, its positive impact on TWS would represent a first confirmation for an enhanced role of consumption complementarities. Table 7 shows the average amount of minutes per day spent in each of the three relevant activities and in TWS across the three decades under investigation. In order to first assess the magnitude of the relation between time spent together and time devoted to the selected activities I use OLS to estimate:

$$
T W S_{i}=\alpha+X_{i} \beta+Z_{i} \gamma+\sum_{k=1}^{3} \theta_{k} t_{i, k}
$$

where the dependent variable, Time Spent with Spouse is regressed against a set of variables $X$ that control for personal characteristics, such as age, education, income, presence of children, area where the individual lives (urban or rural), job status and the matrix $Z$ composed by a set of controls for the day of the week and the season in which the individual kept her diary. The parameters $\theta$ relate to each of the three critical time use variables (household chores, childcare and leisure) and are the main objects of interest in this section. A positive sign for these coefficients indicates that an increase in the time spent in the included activity is related to an increase in the time spent with the spouse. Furthermore, considering that the regressand and the regressors are calculated in minutes, the interpretation of the parameters is quite straightforward as the estimated value indicates the change in TWS in terms of minutes per day that can be linked to a one minute increase in the time devoted to the activity under consideration. The analysis is initially performed separately on females and males and for each wave and is then complemented by the OLS estimation of the following equation ${ }^{35}$ :

$$
T W S_{i}=\alpha+X_{i} \beta+Z_{i} \gamma+S \delta+\sum_{k=1}^{3} \theta_{k} t_{i, k}+\sum_{k=1}^{3} \sum_{j=1}^{4} \lambda_{k, j} t_{i, k, j} s_{j} .
$$

where the three waves are merged in a unique dataset and year effects and all the interaction terms between each time use variable and the year dummies are included in the set of independent variables. In particular, the matrix $S$ contains three dummy variables for the survey years and the

\footnotetext{
${ }^{35}$ Eq. (6) can be simplified into $T W S_{i}=\alpha+X_{i} \beta+Z_{i} \gamma+\theta t_{i, k}$ where each time use variable is individually introduced into the regression. The results obtained by regressing this equation are extremely similar to those reported with respect to eq. (6) and are therefore not presented in the paper.
} 
parameters $\lambda$ are meant to capture the trend effects.

Tables 21 and 22 in the Appendix reports the estimated parameters for the matrices $X$ and $Z$ with respect to eq. (6). These coefficients appear to be fairly robust to any proposed specifications so that I avoid to report them in further specifications. In all, although the results from tables 21 and 22 are not particularly controversial, they suggest some interesting insights into the dynamics of the variables when correlated with TWS. The effect of age substantially differs between women and men, for the former being characterized by a constantly negative parameter (and a positive one with respect to the squared term, suggesting a concave relation between age and the time spent with the husband), while the latter shows a notable degree of variability in both the linear and the quadratic term. Similar differences can be found also for the dummy variable which indicates whether the respondent is unemployed. It is worth to notice that for both men and women the impact of the presence of kids in the family on the amount of time the partners can spend together is generally negative.

The coefficients related to each time use variable obtained running eq. (6) separately for each wave are summarized in Table $8^{36}$. The estimated parameter for leisure is positive for both genders, and in both cases the effect appears to gain relevance over time. For men, in fact, in 1965 one additional minute of leisure would have been related to an increase in the time spent with their spouse of just 0.05 of a minute. The impact of one more minute of leisure in 2003 is certainly more noticeable, as it is estimated in 0.66 of a minute. A statistically significant positive sign (although with a smaller magnitude) also characterizes the coefficient obtained regressing leisure on TWS for women. Taking into consideration the averages reported in table 1, that show a reduction in TWS as we move from the 1975 wave to that of 2003 , the increasing effect of leisure on the dependent variable indicates a change in the composition of the time spent together. The estimated link between leisure and TWS directly relates with the hypothesis of a direct relation between the partners' utility and the quality of the time spent when together and represents a first, solid stepping stone toward a theory explaining the importance gained by time use complementarities within couples.

The parameters related to the time devoted to household chores and childcare also contribute to define a new pattern in the way wives and husbands shape their joint consumption of time. For males, in fact, a constant increase in the average time spent in these activities does not imply

\footnotetext{
${ }^{36}$ All the discussed regressions include the set of control variables shown in tables 21 and 22 . As already mentioned above, the parameters of these variables are always very similar to those reported in tables 21 and 22 and are then not reported.
} 


\begin{tabular}{|c|c|c|c|}
\hline Males & Year 1965 & Year 1975 & Year 2003 \\
\hline Leisure & $\begin{array}{c}0.0525^{* *} \\
(2.46)\end{array}$ & $\begin{array}{c}0.269^{* * *} \\
(9.66)\end{array}$ & $\begin{array}{c}0.669^{* * * *} \\
(56.79)\end{array}$ \\
\hline House Chores & $\begin{array}{c}0.0481^{* * *} \\
(2.98)\end{array}$ & $\begin{array}{c}0.113^{* * *} \\
(6.97)\end{array}$ & $\begin{array}{c}0.0718^{* * *} \\
(9.75)\end{array}$ \\
\hline Childcare & $\begin{array}{c}0.258^{* * *} \\
(7.17)\end{array}$ & $\begin{array}{c}0.427^{* * *} \\
(11.09)\end{array}$ & $\begin{array}{c}0.192^{* * *} \\
(19.23)\end{array}$ \\
\hline $\begin{array}{l}R^{2} \\
\text { Adjusted } R^{2} \\
\text { Observations }\end{array}$ & $\begin{array}{l}0.272 \\
0.271 \\
17043\end{array}$ & $\begin{array}{l}0.207 \\
0.206 \\
20914\end{array}$ & $\begin{array}{l}0.262 \\
0.261 \\
74200\end{array}$ \\
\hline Females & Year 1965 & Year 1975 & Year 2003 \\
\hline Leisure & $\begin{array}{c}0.165^{* * * *} \\
(7.82)\end{array}$ & $\begin{array}{c}0.109^{* * *} \\
(4.37)\end{array}$ & $\begin{array}{c}0.415^{* * *} \\
(43.18)\end{array}$ \\
\hline House Chores & $\begin{array}{c}-0.0949 * * * \\
(-12.41)\end{array}$ & $\begin{array}{r}0.0150 \\
(1.46)\end{array}$ & $\begin{array}{c}-0.0419 * * * \\
(-8.10)\end{array}$ \\
\hline Childcare & $\begin{array}{c}-0.0274^{* *} \\
(-2.20)\end{array}$ & $\begin{array}{c}-0.240^{* * *} \\
(-13.43)\end{array}$ & $\begin{array}{c}-0.00839 \\
(-1.35)\end{array}$ \\
\hline$R^{2}$ & 0.249 & 0.170 & 0.213 \\
\hline Adjusted $R^{2}$ & 0.248 & 0.170 & 0.213 \\
\hline Observations & 25352 & 30777 & 102482 \\
\hline
\end{tabular}

Table 8: OLS Regression, Time Use Variables Coefficients From General Regression

an increase in the magnitude of the (always positive) parameters; The male contribution to house chores and childcare is in present times more relevant in quantitative terms than in previous decades, as seen in table 7 , and it is still linked to an increase in the time the husband spend with the wives. Nonetheless, the marginal contribution of these activities in "explaining" TWS decreases over time. For women, the evolution of the parameters across waves does not define a monotonic pattern. The coefficients are generally of smaller magnitude if compared to those observed for men, and always negative when statistically significant. Although the difference in the size of the estimated parameters for Household Chores between 1965 and 2003 is quite small, the fact that while the total amount of time devoted to these activities between in the same interval of time has dropped considerably, the coefficient for 1965 is still the larger in absolute value suggests a reduction in the across time degree of substitution between household chores and time with the partner. And this 


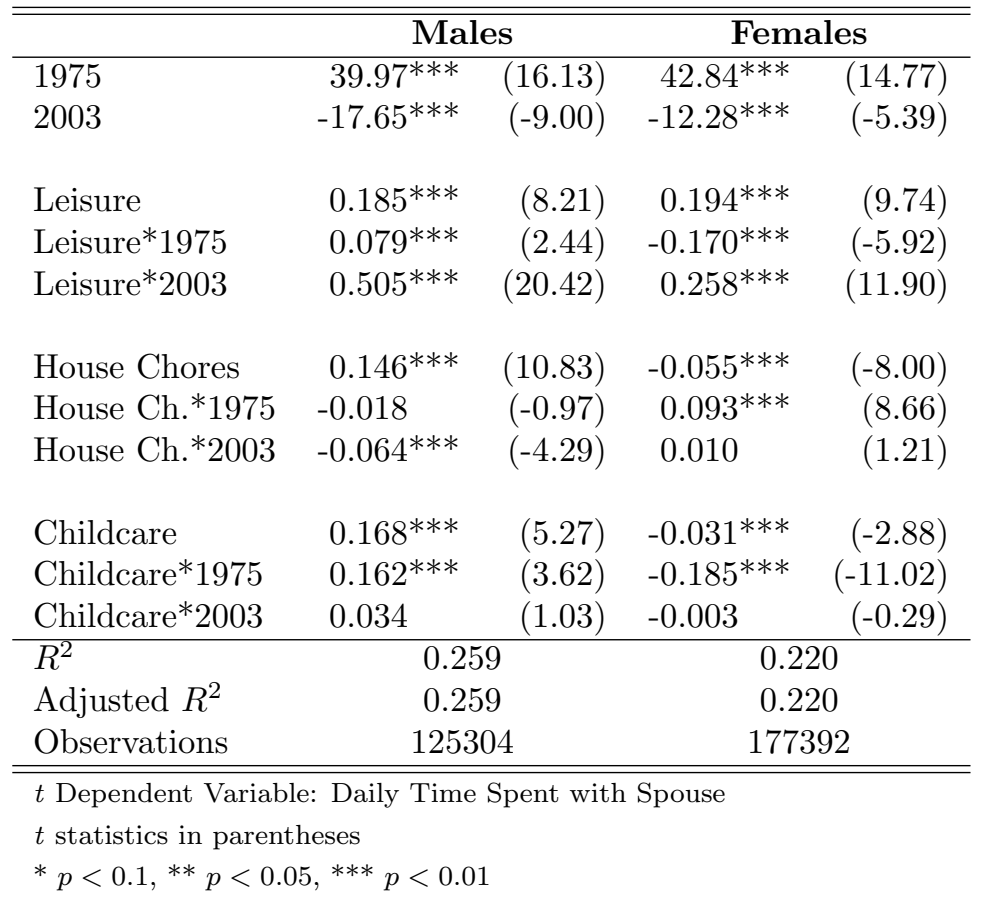

Table 9: OLS Regressions, Coefficients for Year Dummies, Time Use Variables and Interaction Terms

lack of relation between the the dependent variable and its regressors is more evident if we focus on Childcare, for which an increase in the total amount of time across waves is linked to a final coefficient which shows no statistical relation with TWS.

Table 9 presents the results from the estimation of eq. 7 , whose aim is to further investigate the way the relation between the time use explanatory variables and TWS changes over time, by explicitly introducing the interaction terms between surveys and time use variables among the regressors. The set of the year dummies and interaction terms does not include the 1965 wave so that the results can interpreted as changes with respect to this baseline year. The fact that for both men and women the survey year parameters show a change in sign simply reflects the non-monotonic time trend in the amount of time couples spend together, as already highlighted in table 1. Focusing on the time use variables, the emergence in recent years of a relevant link between leisure and time spent with the partner is once more evident. For both men and women the interaction term between leisure and the 2003 wave is characterized by a positive coefficient whose magnitude overcomes that of the non-interacted time variables. In this sense, although the average amount of minutes per day devoted to leisure noticeably increased in the last forty years, 
the marginal explanatory power of this variable with respect to TWS still gains momentum. This kind of regularity can not be observed with respect to the other time use variables. For men, the interaction terms related to household chores define a negative trend which acquire magnitude and statistical significance over time. Hence, the dynamics that characterizes this parameters move in an opposite direction to that identified with respect to leisure. An increase in the average daily amount of time devoted to chores tends to be linked to a reduction in the time spent with the wife. As this effect accompanies the increase in TWS observed between 1965 and 2003 (but not between 1965 and 2003) the marginal contribution of the time spent in chores in explaining the composition of TWS seems to be limited. The corresponding parameters for women show an opposite pattern in terms of signs across interaction terms, but is important to stress that the 2003 interaction terms fails to achieve any statistical significance, so that establishing whether a correlation in the changes in the dependent variable and in the time devoted to household chores exist is not possible. Similar conclusions can be drawn for both sexes with respect to the amount of minutes spent in childcare. Of course as leisure emerges among the included time use variables as the only regressors consistently related to TWS across time and with a praticulary strong link in the last wave, it is important to recall that the way women and their spouses spend their time could have been strongly influenced by the changes in the social context that might have taken place over the spell of time under considerations. The reference is in particular with respect to the female participation to the labour market. In 1965, 30\% of the interviewed women were working fulltime, while in 2003 the corresponding percentage had gone up to $46 \%$. In order to better identify the effects of this intertemporal change, the analysis based on (7) was repeated splitting the sample of women between non-workers and workers. Table 10 shows the average amount of minutes per day spent by working and non-working women in the activities we have been focusing on, while table 11 presents the results for the OLS regressions (the parameters for all the other variables are included in the Appendix, table 23).

After having operated such a division in the sample, although the average figures tend to display similar evolving patterns, the regression results show several differences between the two set of individuals. As for non-working women the estimated coefficients tend to reproduce the same dynamics outlined for all the female sample (and this result can not be considered surprising for the set of non working women being characterised by a higher cardinality than that of the employed 


\begin{tabular}{lcccc}
\hline \hline & $\mathbf{1 9 6 5}$ & $\mathbf{1 9 7 5}$ & $\mathbf{2 0 0 3}$ & Diff.03-65 \\
\hline Not Working Women & & & & \\
Leisure & 20.783 & 12.943 & 31.089 & 10.306 \\
House Chores & 304.343 & 215.489 & 173.367 & -130.976 \\
Childcare & 90.136 & 69.207 & 122.976 & 32.840 \\
Time with Spouse & 247.873 & 351.998 & 294.716 & 46.843 \\
\hline & & & & \\
Working Women & & & & \\
Leisure & 14.206 & 18.303 & 35.314 & 21.108 \\
House Chores & 179.262 & 152.084 & 121.956 & -57.306 \\
Childcare & 33.837 & 34.857 & 62.365 & 28.528 \\
Time with Spouse & 206.281 & 307.733 & 284.385 & 78.104 \\
\hline * Estimated; & \multicolumn{4}{|l}{} \\
All differences presented in the last column are statistically significant at 1\% level.
\end{tabular}

Table 10: Average Time per Day (in Minutes)

ones), the parameters for those women that declare to work full-time sensibly diverge from those observed so far. In particular, although the parameter characterising the link between TWS and leisure per se is still positive and significant, the time trend associated to this variable shows that such a relation is negative in 1975 and potentially non existent in 2003. The estimates for the other time use variable also do not lead to the identification of clear connection between the observed increase in the total TWS for working women and time spent on these activities over the last four decades.

All the sets of results presented in this section suggest the existence of strict correlation between the way partners model their leisure activities and the time they spend together. Furthermore (with possibly the only exception of the coefficients related to working women), such a link stands out from the whole group of estimates for its reinforcement over time. By connecting these results to the assumptions on the relation between time spent together and utility of the partners, as outlined in section 2, the hypothesis that in recent years the time spent together is to be identified more as quality time and less with the simple performance of routinary household activities appears to gain momentum. At this stage no obvious claim can of course be made neither on the direction of the causality of this link nor regarding the possible implications of this correlation on the divorce rates. Nonetheless, with respect to the latter, if the likelihood of divoce is to be linked to the quality of the match between two partners, than a further level of analysis can be implemented on the same data so as to shed some light on how the outlined relations between the time use variables and our measure of togetherness can be then reflected on the quality of the match. In this sense eq. 


\begin{tabular}{|c|c|c|c|c|}
\hline Females & \multicolumn{2}{|c|}{ Non-Working } & \multicolumn{2}{|c|}{ Working } \\
\hline 1975 & $36.66^{* * *}$ & $(4.22)$ & $47.51^{* * *}$ & $(11.46)$ \\
\hline 2003 & $-38.13^{* * *}$ & $(-11.03)$ & $7.11^{* * *}$ & $(2.24)$ \\
\hline Leisure & $0.094^{* * *}$ & $(3.92)$ & $0.369^{* * *}$ & (10.00) \\
\hline Leisure*1975 & -0.059 & $(-1.53)$ & $-0.392^{* * *}$ & $(-8.44)$ \\
\hline Leisure*2003 & $0.396^{* * *}$ & $(14.78)$ & 0.044 & (1.15) \\
\hline House Chores & $-0.130 * * *$ & $(-14.46)$ & 0.005 & $(-0.37)$ \\
\hline House Ch.*1975 & $0.142^{* * *}$ & $(10.32)$ & 0.019 & $(0.98)$ \\
\hline House Ch.*2003 & $0.038 * * *$ & (3.46) & $0.023^{*}$ & (1.60) \\
\hline Childcare & $-0.096^{* * *}$ & $(-7.81)$ & 0.107 & $(4.30)$ \\
\hline Childcare*1975 & $-0.228^{* * *}$ & $(-11.41)$ & $-0.131^{* * *}$ & $(-3.75)$ \\
\hline Childcare*2003 & $0.067^{* * *}$ & $(5.07)$ & $-0.146^{* * *}$ & $(-5.61)$ \\
\hline$R^{2}$ & 0.215 & & 0.233 & \\
\hline Adjusted $R^{2}$ & 0.215 & & 0.233 & \\
\hline Observations & 102322 & & 75070 & \\
\hline
\end{tabular}

Table 11: OLS Regressions, Coefficients for Year Dummies, Time Use Variables and Interaction Terms

6 is used as baseline for performing a set of quantile regressions on the same group of variables already included in the previous estimations. In figures 1 and 2 the parameters obtained by the quantile regression at decile level are plotted for each of the time use variables included among the regressors ${ }^{37}$. The graphs respectively refer to females and males and are presented separately for each year. The estimates can be interpreted as the marginal effects on the time spent with the spouse due to a one minute change of the covariate ${ }^{38}$. The confidence intervals (indicated by the shadowed areas) are obtained via a bootstrap procedure based on a thousand repetitions ${ }^{39}$. The dashed lines indicate the parameters obtained in the corresponding OLS regressions.

By comparing the plotted lines with the OLS estimates it is evident that in some cases the linear regression does not fully capture the "inter-quantile" dynamics of the effects on the dependent variable. It is worth noting that for women, the parameters associated with leisure time tend to show a different dynamics in comparison to those related to household chores and childcare. With respect

\footnotetext{
${ }^{37}$ The independent variables included in the quantile regressions are the same as in the OLS analysis. The complete list of regressors is included in the Appendix. The results of the quantile regressions for the non time use variables are not reported but can of course be made available by the author.

${ }^{38}$ A good summary on how to implement and interpret quantile regressions see Koenker and Hallock (2001).

${ }^{39}$ For the validity of the bootstrap procedure with respect to quantile regressions and the optimal number of repetitions, see Koenker and Hallock (2000) and Andrews and Buchinsky (2000).
} 

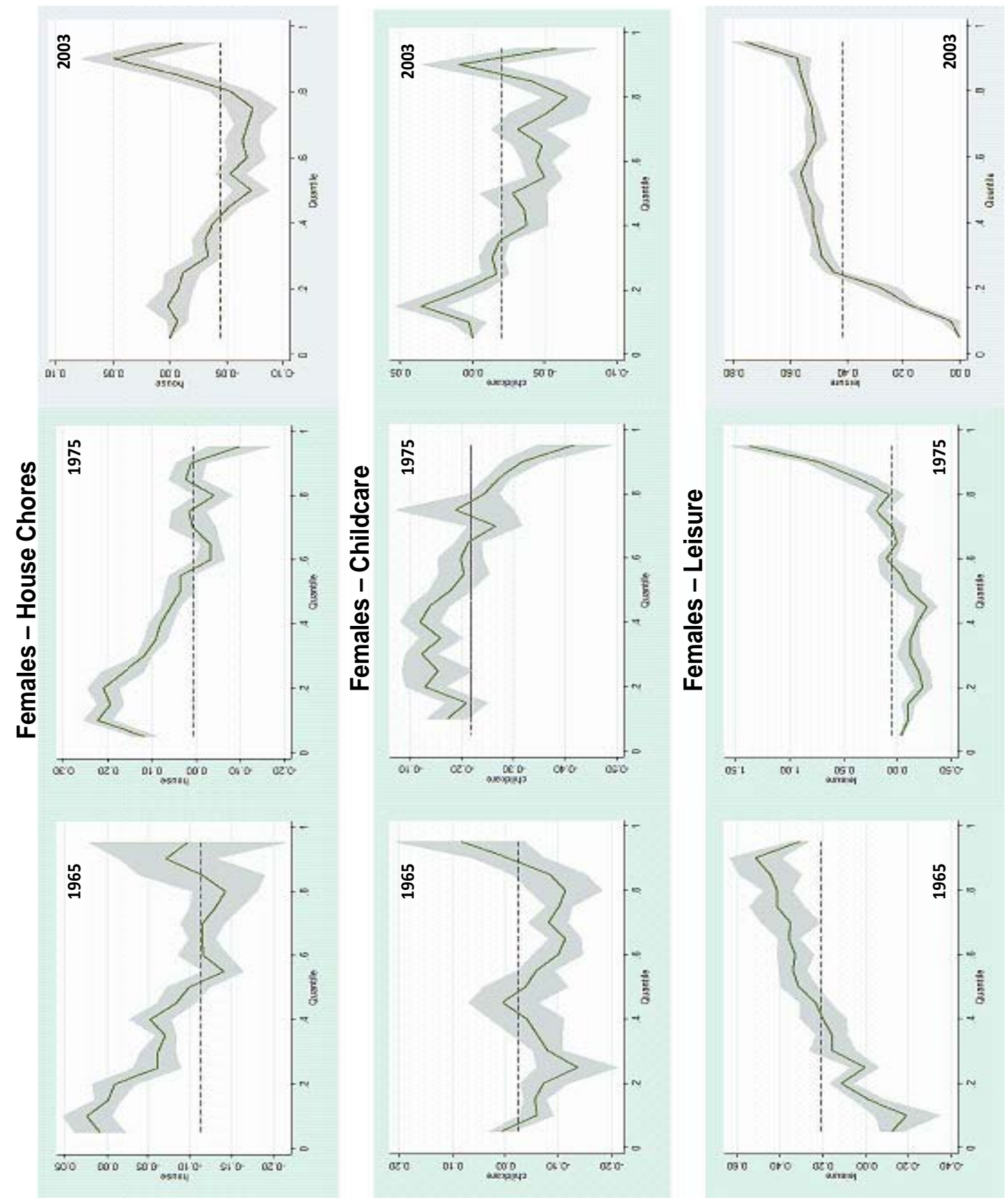

Figure 1: Quantile Regressions - Females. Dependent Variable: Time Spent with Spouse 

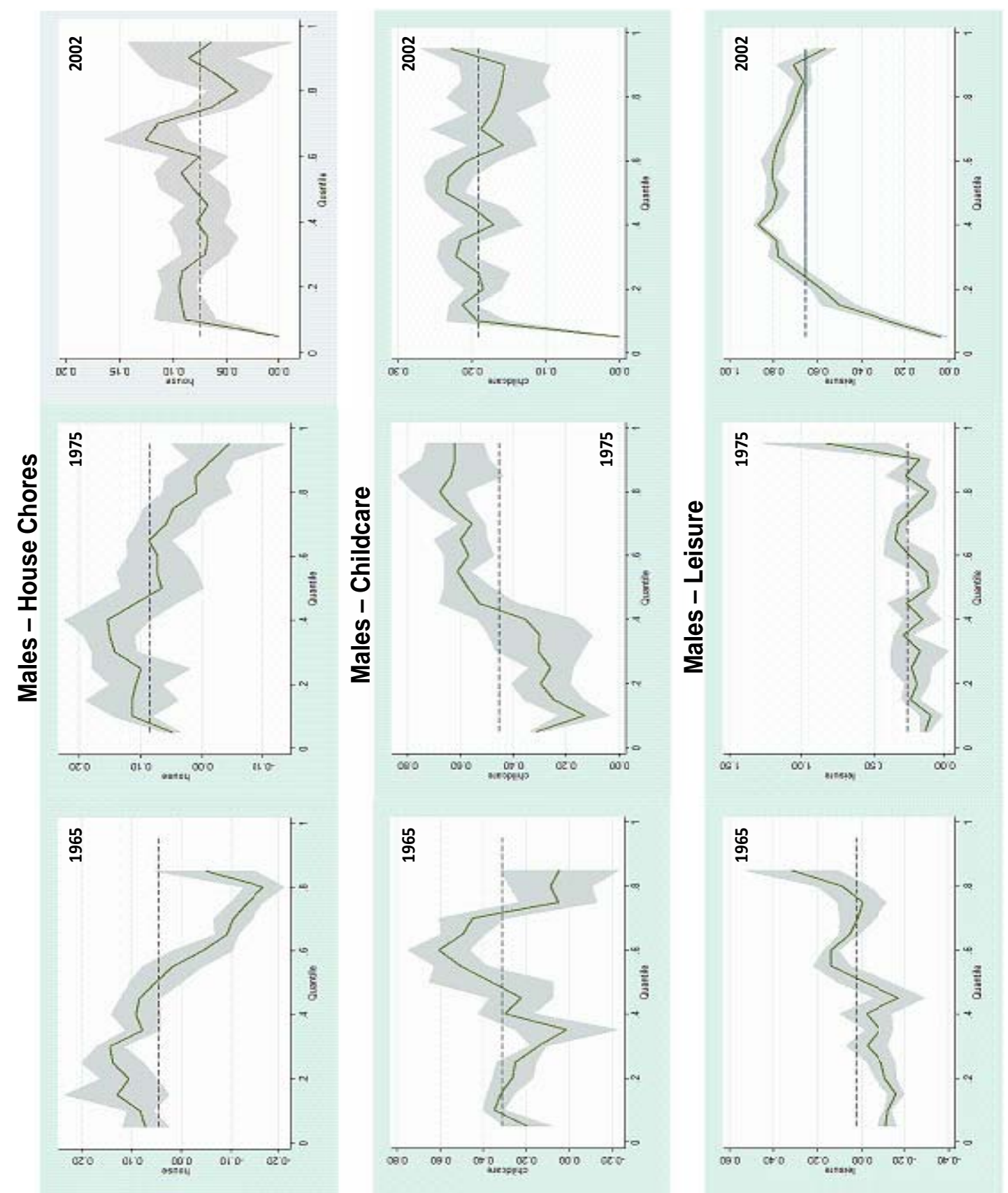

Figure 2: Quantile Regression - Males. Dependent Variable: Time Spent with Spouse 
to these last two variables, in fact, the effect of an increase of the time spent on these activities generally appears to be decreasing (the only notable exception being the coefficients related to childcare in 1965). So for those women who already tend to spend a relatively high amount of time with the partner, the negative between the house and family related activities and "togetherness" is particularly relevant. This evidence was at least partially captured by the negative signs of the OLS coefficients presented in table 8 . The opposite results characterize the impact of a one minute increase in leisure. The coefficients in this case vary considerably across the distribution, with the larger effects being observed on the higher deciles. In particular, a one minute increase in the daily amount of time devoted to leisure is related to an increase in togetherness of only 3 seconds for individuals located in the lowest decile of the distribution, while for individuals in the right tails of the distribution, such an increase is linked to an increase in joint time consumption of almost 45 seconds. This pattern appears to be rather systematic in 1965 and 2003, while the positive sign associated with the OLS parameter in 1975 seems to be largely driven by the huge increase in the parameter values observed with respect to last two deciles.

The signs and the magnitudes of the parameters obtained with the OLS regressions clearly differed between genders. It is therefore not surprising (and actually quite reassuring with respect to the validity of the results commented so far) that the graphs resulting from performing the quantile regressions on the male sample considerably differ from those related to women. The major disparities emerge with respect to the relation between the dependent variable and an increase of the time devoted to childcare. The largely negative effects that characterized the results related to women are now completely overturned. The coefficients for men are steadily positive across deciles, and in particular, the parameters for 2003 appear to be reasonably close to the least square estimate. With respect to an increase in leisure, the results in this case are less straightforward as the shapes of the graphs tend to change overtime. Nonetheless, as already noted for women, both the 1965 and the 2003 estimates show a positive trend across deciles. This particular result can be related to the theoretical assumption proposed in section 2. As spending more quality time together should be seen as a sign of an improvement in the utility level reached by the partners, the relation between leisure time and "togetherness" can be seen as a good proxy for the quality of a match. In this respect, the outlined pattern in the quantile regression coefficients indicates that partners that already spend a relatively high amount of time together tend to increase the time 
with the spouse were their leisure time marginally increased by an additional minute.

Overall, the results obtained through the performance of the quantile regression confirm the pivotal role achieved by leisure in its relation with the extent of togetherness within couples in the last years. The patterns of the estimated parameters, in fact, tend to reinforce the perceived importance of the link between the two variables, already observed through the OLS regressions. The fact that the values of the coefficients with respect to leisure tend to increase both in a intertemporal dimension and across deciles, while such a regularity can not be found for the other time use regressors, points in the direction of the establishment of connection between the joint consumption of leisure time and the quality of a marital match.

\section{Conclusions}

In this paper I investigated the link between the extent and the nature of spouses' commitments in the development of an intra-household surplus and the likelihood of success of the marital union. In particular, the contribution of each partner to the formation of a marital-specific capital is studied through an investigation of the way household chores and childcare are shared within families. The observation of changes in the inter-temporal dynamics related to distribution of responsibilities between spouses is interpreted as evidence for a different influence of social norms on the development of a successful marital union across the last four decades. Thus, the decision to divorce is directly linked to the management of typical household tasks, under the assumption that households in which the husband takes on typically female chores are less likely to dissolve, while couples in which the wife takes on typically male chores are more likely to divorce. Furthermore, an attempt is made to reconcile the empirical tests with a more general theory of allocation of time across different families. In this sense, the analysis is expanded in order to evaluate the validity of the theory of the role played by consumption complementarities between partners in determining the stability of of marriage, as first suggested by Stevenson and Wolfers (2007).

The analysis is conducted in two stages. I first explore the relation between the way partners share their house responsibilities and the likelihood of divorce, making use of several datasets collected within the National Longitudinal Survey series. Taking advantage of panel dimension of the datasets I exploit the presence of a set of questions on the management of household chores in order to disentangle how the changed amount of time spent at home by the partners can effectively play 
a role on the duration of a marriage. Interestingly, the estimated results show that the explanatory power of the documented increase in male participation to house chores over the likelihood of divorce has vanished in the most recent surveys. This evidence can be interpreted as suggesting the establishment among American couples of new regularities that go beyond the household management schemes proposed by theory of production complementarities. Furthermore, as the relation between a more balanced way to share tasks within families and the success of the marital union appears to be relevant only with respect to cohorts of individuals whose marriage took place in the late Sixties, the analysis leaves room for the introduction of new dimensions in the study of the forces characterizing the intra-families dynamics.

In this respect, I complement the study on the NLS by investigating the patterns of time consumption of American couples across four decades, starting in 1965. In this way, I can measure to which extent consumption complementarites have substituted production complementarities in determining the degree of "togetherness" across couples. Although, given the way data are collected, I am forced to rely on time consumption as a proxy for consumption of any other good, the obtained picture is rather complete. Over the years under consideration, partners clearly show a tendency to modify the structure of the time they spend together, favoring a considerable increase in the time devoted to joint leisure activities. The time spent in household chores, childcare and other activities shows different impacts. In particular, my findings suggest that although the amount of time men spend in childcare is increasing, this phenomenon does not positively relate to the time spent with the spouse, which is then dedicated to other activities. Results with respect to women change considerably depending on the working status of the individual, suggesting a lower degree of dynamics in the time consumption trends for working women. Furthermore, the estimates from a quantile regression procedure show how the relation between the time spouses spend together and the average amount of minutes per day devoted to leisure activities can also be interpreted as a proxy for the quality of the marital match. In this sense, if we consider the distribution of the variable "Time with Spouse", a one minute increase in the daily amount of time devoted to leisure is related to an increase in togetherness of only 3 seconds for individuals located in the lowest decile of the distribution, while for individuals in the right tails of the distribution, such an increase is linked to an increase in joint time consumption of almost 45 seconds.

The implications of this paper suggest a number of questions for further research. In particular, 
the possibility to exactly separate the effects on the likelihood of divorce due the existence of consumption complementarities from those that can be linked to self-selection into market appears as a relevant empirical task. Furthermore, the analysis performed in order to test for the relevance of consumption complementarities can probably be enhanced by making use of data on actual consumption of goods instead of time, so to obtain a clearer image of the changes in consumption preferences over time. 


\section{References}

Abbring, J. H., And G. J. V. D. Berg (2007): "The unobserved heterogeneity distribution in duration analysis," Biometrika, 94(1), 87-99.

Aguiar, M., And E. Hurst (2007): "Measuring Trends in Leisure: The Allocation of Time over Five Decades," The Quarterly Journal of Economics, 122(3), 969-1006.

(2008): "The Increase in Leisure Inequality," NBER Working Papers 13837, National Bureau of Economic Research, Inc.

Akerlof, G. A. (1980): "A Theory of Social Custom, of Which Unemployment May be One Consequence," The Quarterly Journal of Economics, 94(4), 749-75.

Akerlof, G. A., and R. E. Kranton (2000): "Economics And Identity," The Quarterly Journal of Economics, 115(3), 715-753.

Anderson, W. L., And D. W. Little (1999): "All's Fair: War and Other Causes of Divorce from a Beckerian Perspective," American Journal of Economics and Sociology, 58(4), 901-922.

Andrews, D. W. K., And M. Buchinsky (2000): "A Three-Step Method for Choosing the Number of Bootstrap Repetitions," Econometrica, 68(1), 23-52.

Baker, M. J., And J. P. Jacobsen (2007): "Marriage, Specialization, and the Gender Division of Labor," Journal of Labor Economics, 25, 763-793.

Barham, V., R. A. Devlin, and J. Yang (2009): "A theory of rational marriage and divorce," European Economic Review, 53(1), 93-106.

Becker, G. S. (1973): "A Theory of Marriage: Part I," Journal of Political Economy, 81(4), 813-46. 
Becker, G. S., E. M. Landes, and R. T. Michael (1977): "An Economic Analysis of Marital Instability," Journal of Political Economy, 85(6), 1141-87.

Bergstrom, T. C. (1996): "Economics in a Family Way," Journal of Economic Literature, 34(4), 1903-1934.

Blau, F. D., And L. M. Kahn (2007): "Changes in the Labor Supply Behavior of Married Women: 19802000," Journal of Labor Economics, 25, 393-438.

Brines, J., And K. Joyner (1999): "The Ties That Bind: Principles of Cohesion in Cohabitation and Marriage," American Sociological Review, 64, 333-355.

Browning, M., And P. A. ChiAppori (1998): "Efficient Intra-Household Allocations: A General Characterization and Empirical Tests," Econometrica, 66(6), 1241-1278.

Browning, M., P.-A. Chiappori, and V. Lechene (2006): "Collective and Unitary Models: A Clarification," Review of Economics of the Household, 4(1), 5-14.

Burda, M. C., D. S. Hamermesh, and P. Weil (2007): "Total Work, Gender and Social Norms," CEPR Discussion Papers 6232, C.E.P.R. Discussion Papers.

Burdett, K., And M. G. Coles (1998): "Separation cycles," Journal of Economic Dynamics and Control, 22(7), 1069-1090.

Burdett, K., R. Imai, and R. Wright (2004): "Unstable Relationships," Frontiers of Macroeconomics, 1(1), 1-42.

Cherlin, A. J. (2004): "The Deinstitutionalization of American Marriage," Journal of Marriage and Family, 66, 848-861.

Cornelius, T. J. (2003): "A Search Model of Marriage and Divorce," Review of Economic Dynamics, 6(1), 135-155.

Datta Gupta, N., and L. S. Stratton (2008): "Institutions, Social Norms, and Bargaining Power: An Analysis of Individual Leisure Time in Couple Households," IZA Discussion Papers 3773, Institute for the Study of Labor (IZA). 
Dush, C. M. K., C. L. Cohan, and P. R. Amato (2003): "The Relationship Between Cohabitation and Marital Quality and Stability: Change Across Cohorts?," Journal of Marriage and Family, 65(3), 539-549.

Fernandez, R., N. Guner, and J. Knowles (2005): "Love and Money: A Theoretical and Empirical Analysis of Household Sorting and Inequality," The Quarterly Journal of Economics, 120(1), 273-344.

Francesconi, M., and A. Muthoo (2003): "An Economic Model of Child Custody," (857).

FriedberG, L. (1998): "Did Unilateral Divorce Raise Divorce Rates? Evidence from Panel Data," American Economic Review, 88(3), 608-627.

Goldin, C. (2006): "The Quiet Revolution That Transformed Women's Employment, Education, and Family," The American Economic Review, 96(2), 1-21.

Gray, J. S. (1998): "Divorce-Law Changes, Household Bargaining, and Married Women's Labor Supply," American Economic Review, 88(3), 628-42.

Greenwood, J., and N. Guner (2004): "Marriage and Divorce since World War II: Analyzing the Role of Technological Progress on the Formation of Households," No. 10772.

Gronau, R. (1980): "Home Production-A Forgotten Industry," The Review of Economics and Statistics, 62(3), 408-16.

Guryan, J., E. Hurst, and M. S. Kearney (2008): "Parental Education and Parental Time With Children," NBER Working Papers 13993, National Bureau of Economic Research, Inc.

Gutierrez, R. G. (2002): "Parametric Frailty and Shared Frailty Survival Models," Stata Journal, $2(1), 22-44$.

Hamermesh, D. S. (2002): "Timing, Togetherness and Time Windfall," Journal of Population Economics, 15, 601-623.

— (2007): "Time to Eat: Household Production under Increasing Income Inequality," American Journal of Agricultural Economics, 89(4), 852-863.

Hart, O. (1995): Firms, Contracts, and Financial Structure. Claredon Press. 
Hosmer, D. W., S. Lemeshow, And S. May (2008): Applied Survival Analysis. John Wiley and Sons, New Jersey.

Hougaard, P. (1986): "Survival Models for Heterogeneous Populations Derived from Stable Distributions," Biometrika, 73, 387-396.

Jenkins, S. P. (1995): "Easy Estimation Methods for Discrete-Time Duration Models," Oxford Bulletin of Economics and Statistics, 57(1), 129-38.

_ (1998): "Discrete time proportional hazards regression," Stata Technical Bulletin, 7(39).

_ (2005): "Survival Analysis," Mimeo, ISER-University of Essex.

Koenker, R., and K. F. Hallock (2000): "Quantile Regression: An Introduction," Paper prepared for the Journal of Economic Perspectives "Symposium on Econometric Tools".

(2001): “Quantile Regression,” Journal of Economic Perspectives, 15(4), 143-156.

Laffont, J.-J., and D. Martimort (2002): The Theory of Incentives. Princeton University Press.

Leamer, E. E. (1978): Specification Searches. John Wiley and Sons, Inc.

Lillard, L., M. Brien, and L. Waite (1995): "Pre-Marital Cohabitation and Subsequent Marital Dissolution: A Matter of Self-Selection?," Demography, 32, 437-458.

LindBeck, A. (1997): "Incentives and Social Norms in Household Behavior," American Economic Review, 87(2), 370-77.

Lundberg, S., And R. A. Pollak (1993): "Separate Spheres Bargaining and the Marriage Market," Journal of Political Economy, 101(6), 988-1010.

(1994): "Noncooperative Bargaining Models of Marriage," American Economic Review, $84(2), 132-37$.

- (2007): "The American Family and Family Economics," Journal of Economic Perspectives, $21(2), 3-26$.

Mortensen, D. T. (1988): "Matching: Finding a Partner for Life or Otherwise," American Journal of Sociology, 94, S215-S240. 
Pollak, R. (2003): "Gary Becker's Contribution to Family and Household Economics," Review of Economics of the Household, 1(1), 111-141.

Ramey, V. A. (2008): "Time Spent in Home Production in the 20th Century: New Estimates from Old Data," NBER Working Papers 13985, National Bureau of Economic Research, Inc.

Rasul, I. (2006a): "The Economics of Child Custody," Economica, 73, 1-25.

— (2006b): "Marriage Markets and Divorce Laws," Journal of Law, Economics and Organization, 22(1), 30-69.

Shimer, R., And L. Smith (2000): "Assortative Matching and Search," Econometrica, 68(2), $343-370$.

Smith, L. (2006): "The Marriage Model with Search Frictions," Journal of Political Economy, 114(6), 1124-1146.

Stevenson, B. (2007): "Divorce-Law Changes, Household Bargaining, and Married Women's Labor Supply Revisited," Working Paper Series 07-03, Population Studies Center - University of Pennsylvania.

Stevenson, B., and J. Wolfers (2007): "Marriage and Divorce: Changes and Their Driving Forces," Journal of Economic Perspectives, 21(2), 27-52.

Thomson, E., and U. Colella (1992): "Cohabitation and Marital Stability: Quality or Commitment?," Journal of Marriage and the Family, 54(2), 259-267.

WeIss, Y. (1997): "The formation and dissolution of families: Why marry? Who marries whom? And what happens upon divorce," in Handbook of Population and Family Economics, ed. by M. R. Rosenzweig, and O. Stark, no. 1. Elsevier.

Weiss, Y., And R. J. Willis (1985): "Children as Collective Goods and Divorce Settlements," Journal of Labor Economics, 3(3), 268-292.

- (1997): "Match Quality, New Information, and Marital Dissolution," Journal of Labor Economics, 15(1), S293-329. 
Wolfers, J. (2006): "Did Unilateral Divorce Laws Raise Divorce Rates? A Reconciliation and New Results," American Economic Review, 96(5), 1802-1820.

Wooldridge, J. M. (2001): Econometric Analysis of Cross Section and Panel Data. MIT Press. 


\section{Appendix 1 - National Longitudinal Surveys}

Description of the variables:

1. Marital Status: dependent variable; dummy variable, 0 if married, 1 if divorced;

2. Duration of Marriage: duration in months;

3. North/South: dummy variable, 0 if the respondent lives in the Northern part of the US, 1 otherwise;

4. White, Black, Other Race: dummy variables;

5. Employment Status: dummy variable, 1 if the respondent works full-time or part-time, 0 otherwise;

6. Difference in the Number of Kids (NLSY79 only): difference between the desired number of kids in 1979 and the actual number of children at time of the interview. 


\begin{tabular}{lccccc}
\hline \hline Variable & $\begin{array}{c}\text { Num. of } \\
\text { Observations }\end{array}$ & Mean & St. Dev. & Min. & Max \\
\hline NLSMW & & & & & \\
Marital Status & 52982 & .01369 & .1162 & 0 & 1 \\
Duration of Marriage & 52269 & 330.9271 & 141.9804 & 1 & 780 \\
Number of Marriages & 52982 & 1.0456 & .2745 & 0 & 4 \\
Age & 52982 & 49.9367 & 10.4286 & 30 & 80 \\
North/South & 52701 & .3822 & .4859 & 0 & 1 \\
White & 52982 & .7583 & .4281 & 0 & 1 \\
Black & 52982 & .2264 & .4185 & 0 & 1 \\
Other Race & 52982 & .0154 & .1229 & 0 & 1 \\
Number of Kids & 52811 & 1.9434 & 1.7810 & 0 & 16 \\
Enrolled in Education & 52982 & .0159 & .1252057 & 0 & 1 \\
Years of Education & 52982 & 12.7299 & 8.6438 & 0 & 18 \\
Employment Status & 50165 & .4138 & .4925244 & 0 & 1 \\
Weekly Hours of Work & 52982 & 14.1008 & 18.8842 & 0 & 168 \\
Wage & 45327 & 29.5305 & 73.76072 & 0 & 2500 \\
Family Income & 49973 & 10639.15 & 7855.32 & 0 & 201795 \\
\hline NLSYW & & & & & \\
Marital Status & 52987 & 0.0339 & 0.1808 & 0 & 1 \\
Duration of Marriage & 52987 & 87.8962 & 60.2198 & 12 & 3.044523 \\
Number of Marriages & 52987 & 1.1172 & 0.3593 & 1 & 4 \\
Age & 52987 & 33.9355 & 10.3581 & 14 & 61 \\
North/South & 52984 & 0.4081 & 0.4915 & 0 & 1 \\
White & 52987 & 0.7730 & 0.4188 & 0 & 1 \\
Black & 52987 & 0.2165 & 0.4118 & 0 & 1 \\
Other Race & 52987 & 0.0105 & 0.1017 & 0 & 1 \\
Number of Kids & 52673 & 1.8638 & 1.4115 & 0 & 12 \\
Enrolled in Education & 52987 & 0.0573 & 0.2324 & 0 & 1 \\
Years of Education & 52886 & 12.477 & 2.4824 & 0 & 18 \\
Employment Status & 42863 & 0.4779 & 0.4995 & 0 & 1 \\
Weekly Hours of Work & 43726 & 34.6036 & 13.2472 & 0 & 168 \\
Wage & 44327 & 56.834 & 210.1157 & 0 & 19586.41 \\
Family Income (categ.) & 51035 & 8.4466 & 3.4513 & 0 & 13 \\
\hline \hline
\end{tabular}

Table 12: List of Regressors, NLSMW and NLSYW 


\begin{tabular}{lccccc}
\hline \hline Variable & $\begin{array}{c}\text { Num. of } \\
\text { Observations }\end{array}$ & Mean & St. Dev. & Min. & Max \\
\hline NLSY79 - Males & 41968 & 0.04086 & 0.19798 & 0 & 1 \\
Marital Status & 40528 & 7.0267 & 5.4058 & 1 & 32 \\
Duration of Marriage & 41968 & 1.1342 & 0.37208 & 1 & 4 \\
Number of Marriages & 41968 & 31.0489 & 6.14346 & 17 & 47 \\
Age & 41784 & 0.73887 & 0.43926 & 0 & 1 \\
White & 41784 & 0.20369 & 0.40275 & 0 & 1 \\
Other Race & 39743 & 1.4194 & 1.28692 & 0 & 10 \\
Number of Kids & 39743 & 1.109 & 1.84132 & -9 & 19 \\
Diff. in Number of Kids & 41968 & 0.04079 & 0.19781 & 0 & 1 \\
Enrolled in Education & 41505 & 13.0686 & 4.65119 & 0 & 95 \\
Years of Education & 31676 & 0.69163 & 0.46183 & 0 & 1 \\
Employment Status & 24484 & 36.3818 & 19.1515 & 0 & 168 \\
Weekly Hours of Work & 34909 & 2007.21 & 46478.9 & 0 & 6000000 \\
Wage & 36408 & 48160.1 & 74419 & 0 & 1057448 \\
Family Income & & & & & \\
\hline & & & & & \\
NLSY79 - Females & 50545 & 0.04171 & 0.19992 & 0 & 1 \\
Marital Status & 49220 & 7.7878 & 5.7724 & 1 & 33 \\
Duration of Marriage & 50545 & 1.15003 & 0.39568 & 1 & 5 \\
Number of Marriages & 50545 & 30.3641 & 6.29048 & 17 & 47 \\
Age & 50172 & 0.74727 & 0.43458 & 0 & 1 \\
White & 50172 & 0.19274 & 0.39445 & 0 & 1 \\
Other Race & 48025 & 1.53447 & 1.31964 & 0 & 10 \\
Number of Kids & 1.0034 & 1.882 & -7 & 25 \\
Diff. in Number of Kids & 87768 & 0.04869 & 0.21522 & 0 & 1 \\
Enrolled in Education & 50545 & 13.2996 & 4.95882 & 0 & 95 \\
Years of Education & 49974 & 0.46194 & 0.49855 & 0 & 1 \\
Employment Status & 45935 & 18.7992 & 19.7919 & 0 & 168 \\
Weekly Hours of Work & 34969 & 1317.25 & 26154.9 & 0 & 2940000 \\
Wage & 36481 & 45060.1 & 74759 & 0 & 1057448 \\
Family Income & 42389 & & & & \\
\hline \hline
\end{tabular}

Table 13: List of Regressors, NLSY79 


\begin{tabular}{lclll}
\hline \hline & \multicolumn{2}{c}{ NLSMW } & \multicolumn{2}{c}{ NLSMW } \\
& & & Unobs. Heterog. \\
\hline Duration of Marriage & $-0.528^{* * *}$ & $(-2.64)$ & $-0.524^{* *}$ & $(-2.51)$ \\
Number of Marriage & 0.370 & $(1.44)$ & 0.444 & $(1.40)$ \\
Age & $0.394^{* * *}$ & $(4.48)$ & $0.399^{* * *}$ & $(4.43)$ \\
Age & $-0.003^{* * *}$ & $(-4.14)$ & $-0.003^{* * *}$ & $(-4.12)$ \\
Region & -0.089 & $(-0.56)$ & -0.084 & $(-0.51)$ \\
White & -0.225 & $(-0.38)$ & -0.214 & $(-0.36)$ \\
Black & -0.638 & $(-1.05)$ & -0.625 & $(-1.01)$ \\
Number of Children & $-0.160^{* * *}$ & $(-2.86)$ & $-0.159^{* * *}$ & $(-2.81)$ \\
Enrolled in Educ. & $0.796^{* *}$ & $(2.22)$ & $0.799^{* *}$ & $(2.08)$ \\
Education Level & 0.038 & $(1.27)$ & 0.042 & $(1.30)$ \\
Employed & $0.591^{* *}$ & $(2.43)$ & $0.605^{* *}$ & $(2.45)$ \\
Weekly Hours of Work & $0.014^{* *}$ & $(2.35)$ & $0.014^{* *}$ & $(2.36)$ \\
Wage & 0.001 & $(0.49)$ & 0.001 & $(0.46)$ \\
Family Income & $-0.000^{*}$ & $(-1.69)$ & $-0.000^{*}$ & $(-1.70)$ \\
Grocery Wife & -0.241 & $(-1.19)$ & -0.248 & $(-1.21)$ \\
Grocery Husband & $-1.366^{* * *}$ & $(-3.72)$ & $-1.381^{* * *}$ & $(-3.72)$ \\
Childcare Wife & 0.106 & $(0.67)$ & 0.112 & $(0.69)$ \\
Childcare Husband & $-0.643^{* *}$ & $(-1.97)$ & $-0.648^{* *}$ & $(-1.96)$ \\
Cooking Wife & -0.048 & $(-0.22)$ & -0.049 & $(-0.22)$ \\
Cooking Husband & -0.374 & $(-0.88)$ & -0.385 & $(-0.90)$ \\
Dishes Wife & 0.112 & $(0.51)$ & 0.107 & $(0.48)$ \\
Dishes Husband & -0.136 & $(-0.36)$ & -0.134 & $(-0.35)$ \\
House Keep. Wife & -0.203 & $(-0.88)$ & -0.203 & $(-0.87)$ \\
House Keep. Husband & $-1.189^{* *}$ & $(-2.08)$ & $-1.201^{* *}$ & $(-2.08)$ \\
Clothes Wife & -0.337 & $(-1.55)$ & -0.340 & $(-1.54)$ \\
Clothes Husband & 0.153 & $(0.30)$ & 0.162 & $(0.32)$ \\
Gardening Wife & 0.204 & $(1.03)$ & 0.226 & $(1.10)$ \\
Gardening Husband & $-1.713^{* * *}$ & $(-7.96)$ & $-1.719^{* * *}$ & $(-7.89)$ \\
Constant & $-11.83^{* * *}$ & $(-4.95)$ & $-12.28^{* * *}$ & $(-4.66)$ \\
\hline Log lik. & -995.1 & & -995.0 & \\
Chi-2 & 377.2 & & 234.0 & \\
Observations & 25537 & & 25537 & \\
\hline \hline Dependent Vate: & & & \\
\hline
\end{tabular}

Dependent Variable: Marital Status, $0=$ Married, $1=$ Divorce

Table 14: Clog-log analysis - Mature Women 


\begin{tabular}{lclcl}
\hline \hline & \multicolumn{2}{c}{ NLSYW } & \multicolumn{2}{c}{ NLSYW } \\
& \multicolumn{2}{c}{ Unobs. Heterog. } \\
\hline Duration of Marriage & $0.510^{* * *}$ & $(3.88)$ & $0.890^{* * *}$ & $(4.47)$ \\
Number of Marriages & $0.592^{* * *}$ & $(4.22)$ & $0.832^{* * *}$ & $(4.15)$ \\
Age & $0.675^{* * *}$ & $(10.77)$ & $0.755^{* * *}$ & $(10.18)$ \\
Age & $-0.008^{* * *}$ & $(-10.03)$ & $-0.009^{* * *}$ & $(-9.60)$ \\
Region & $-0.251^{* * *}$ & $(-2.77)$ & $-0.269^{* *}$ & $(-2.29)$ \\
White & $1.251^{*}$ & $(1.76)$ & $1.546^{*}$ & $(1.81)$ \\
Black & 1.028 & $(1.44)$ & 1.407 & $(1.63)$ \\
Number of Children & $-0.071^{*}$ & $(-1.94)$ & $-0.113^{* *}$ & $(-2.28)$ \\
Enrolled in Educ. & $0.661^{* * *}$ & $(4.55)$ & $0.692^{* * *}$ & $(3.93)$ \\
Education Level & $0.062^{* * *}$ & $(3.00)$ & $0.077^{* * *}$ & $(2.85)$ \\
Employed & $1.021^{* * *}$ & $(9.42)$ & $1.059^{* * *}$ & $(8.61)$ \\
Weekly Hours of Work & $0.018^{* * *}$ & $(5.51)$ & $0.022^{* * *}$ & $(5.39)$ \\
Wage & $-0.001^{* *}$ & $(-2.47)$ & $-0.001^{* * *}$ & $(-2.62)$ \\
Family Income (Cat.) & $-0.220^{* * *}$ & $(-15.12)$ & $-0.264^{* * *}$ & $(-12.79)$ \\
Grocery Wife & -0.233 & $(-1.55)$ & -0.251 & $(-1.33)$ \\
Grocery Husband & -0.247 & $(-1.47)$ & -0.275 & $(-1.34)$ \\
Childcare Wife & 0.082 & $(0.69)$ & 0.067 & $(0.44)$ \\
Childcare Husband & $-0.467^{* * *}$ & $(-3.54)$ & $-0.605^{* * *}$ & $(-3.62)$ \\
Cooking Wife & 0.051 & $(0.36)$ & 0.035 & $(0.20)$ \\
Cooking Husband & 0.036 & $(0.22)$ & 0.034 & $(0.17)$ \\
Dishes Wife & -0.139 & $(-1.17)$ & -0.172 & $(-1.15)$ \\
Dishes Husband & -0.096 & $(-0.61)$ & -0.155 & $(-0.81)$ \\
House Keep. Wife & -0.054 & $(-0.42)$ & -0.0922 & $(-0.56)$ \\
House Keep. Husband & 0.075 & $(0.46)$ & 0.047 & $(0.24)$ \\
Clothes Wife & $-0.245^{*}$ & $(-1.80)$ & $-0.370^{* *}$ & $(-2.11)$ \\
Clothes Husband & -0.244 & $(-1.28)$ & -0.282 & $(-1.19)$ \\
Gardening Wife & $0.470^{* * *}$ & $(3.70)$ & $0.635^{* * *}$ & $(3.75)$ \\
Gardening Husband & $-0.400^{* * *}$ & $(-3.47)$ & $-0.538^{* * * *}$ & $(-3.65)$ \\
Constant & $-19.41^{* * *}$ & $(-14.41)$ & $-22.90^{* * *}$ & $(-12.14)$ \\
\hline Log likelihood & -2177.8 & & -2165.3 & \\
Chi-2 & 924.9 & & 359.7 & \\
Observations & 22671 & & 22671 & \\
\hline \hline Dependent Varabe: & & & \\
\hline
\end{tabular}

Dependent Variable: Marital Status, $0=$ Married, $1=$ Divorce

Table 15: Clog-log analysis - Young Women 


\begin{tabular}{lclll}
\hline \hline NLSY79 & \multicolumn{2}{c}{ Men } & \multicolumn{2}{c}{ Men } \\
& \multicolumn{2}{c}{ Unobs. Heterog. } \\
\hline Duration of Marriage & $-0.607^{* * *}$ & $(-2.75)$ & $-0.608^{* * *}$ & $(-2.73)$ \\
Number of Marriages & 0.213 & $(0.46)$ & 0.213 & $(0.46)$ \\
Age & $0.818^{* * *}$ & $(4.60)$ & $0.822^{* * *}$ & $(4.40)$ \\
Age $^{2}$ & $-0.013^{* * *}$ & $(-4.69)$ & $-0.013^{* * *}$ & $(-4.53)$ \\
Number of Children & $-1.762^{* * *}$ & $(-12.81)$ & $-1.765^{* * *}$ & $(-12.24)$ \\
Education Level & -0.027 & $(-0.55)$ & -0.026 & $(-0.52)$ \\
Employed & 0.006 & $(0.02)$ & 0.002 & $(0.01)$ \\
Wage & 0.000 & $(0.62)$ & 0.000 & $(0.61)$ \\
Family Income & 0.000 & $(0.62)$ & 0.000 & $(0.63)$ \\
Urban or Rural & 0.082 & $(0.35)$ & 0.081 & $(0.34)$ \\
North-East & -0.273 & $(-0.70)$ & -0.279 & $(-0.70)$ \\
North-Center & $0.671^{* *}$ & $(2.07)$ & $0.670^{* *}$ & $(2.06)$ \\
South & $0.774^{* *}$ & $(2.57)$ & $0.773^{* *}$ & $(2.55)$ \\
White & 0.142 & $(0.34)$ & 0.142 & $(0.34)$ \\
Black & -0.023 & $(-0.05)$ & -0.020 & $(-0.04)$ \\
Resp. Childcare & 0.004 & $(0.02)$ & 0.004 & $(0.02)$ \\
Resp. Cooking & 0.017 & $(0.04)$ & 0.019 & $(0.05)$ \\
Resp. Cleaning Dishes & 0.425 & $(1.17)$ & 0.422 & $(1.15)$ \\
Resp. Errands & 0.094 & $(0.45)$ & 0.092 & $(0.43)$ \\
Resp. Grocery & -0.167 & $(-0.67)$ & -0.167 & $(-0.67)$ \\
Resp. Housekeeping & -0.162 & $(-0.52)$ & -0.160 & $(-0.51)$ \\
Resp. Clothes & -0.259 & $(-0.51)$ & -0.262 & $(-0.52)$ \\
Resp. House Maintenance & -0.019 & $(-0.08)$ & -0.020 & $(-0.08)$ \\
Resp. Outdoor Chores & $-0.658^{* * *}$ & $(-2.67)$ & $-0.660^{* * *}$ & $(-2.65)$ \\
Resp. Paperwork & $0.605^{* *}$ & $(2.53)$ & $0.602^{* *}$ & $(2.47)$ \\
Constant & $-11.80^{* * *}$ & $(-4.76)$ & $-11.86^{* * *}$ & $(-4.50)$ \\
\hline Log lik. & -354.3 & & -354.3 & \\
Chi-2 & 332.2 & & 199.9 & \\
Observations & 3019 & & 3019 & \\
Dependent Variable: Marital Status, $0=$ Married, $1=$ Divorce & \\
& & & &
\end{tabular}

Table 16: Clog-log analysis - NLSY79, MEN 


\begin{tabular}{lclll}
\hline \hline NLSY79 & \multicolumn{2}{c}{ Women } & \multicolumn{2}{c}{ Women } \\
& & & Unobs. Heterog. \\
\hline Duration of Marriage & $-0.743^{* * *}$ & $(-5.58)$ & $-0.854^{* * *}$ & $(-4.79)$ \\
Number of Marriages & 0.253 & $(1.29)$ & 0.266 & $(1.13)$ \\
Age & $0.273^{* * *}$ & $(2.80)$ & $0.392^{* * *}$ & $(3.07)$ \\
Age & $-0.003^{* *}$ & $(-2.34)$ & $-0.005^{* * *}$ & $(-2.69)$ \\
Number of Children & $-0.215^{* * *}$ & $(-3.45)$ & $-0.278^{* * *}$ & $(-3.64)$ \\
Education Level & $0.119^{* * *}$ & $(3.49)$ & $0.130^{* * *}$ & $(3.26)$ \\
Employed & $0.495^{* * *}$ & $(3.35)$ & $0.466^{* * *}$ & $(2.97)$ \\
Wage & 0.000 & $(1.17)$ & 0.000 & $(1.24)$ \\
Family Income & $-0.000^{* * *}$ & $(-12.50)$ & $-0.000^{* * *}$ & $(-11.97)$ \\
Urban or Rural & $0.438^{* * *}$ & $(3.28)$ & $0.474^{* * *}$ & $(3.05)$ \\
North-East & -0.138 & $(-0.61)$ & -0.137 & $(-0.52)$ \\
North-Center & 0.267 & $(1.53)$ & 0.287 & $(1.37)$ \\
South & 0.101 & $(0.65)$ & 0.134 & $(0.72)$ \\
White & 0.325 & $(1.15)$ & 0.391 & $(1.14)$ \\
Black & 0.035 & $(0.11)$ & 0.121 & $(0.32)$ \\
Resp. Childcare & -0.110 & $(-0.44)$ & -0.025 & $(-0.08)$ \\
Resp. Cooking & $-0.686^{* * *}$ & $(-3.42)$ & $-0.801^{* * *}$ & $(-3.07)$ \\
Resp. Dishes & 0.014 & $(0.06)$ & 0.053 & $(0.19)$ \\
Resp. Errands & $0.465^{* * *}$ & $(3.26)$ & $0.541^{* * *}$ & $(3.14)$ \\
Resp. Grocery & -0.284 & $(-1.45)$ & -0.368 & $(-1.54)$ \\
Resp. House Keeping & $0.451^{*}$ & $(1.72)$ & 0.408 & $(1.29)$ \\
Resp. Clothes & -0.122 & $(-0.55)$ & -0.174 & $(-0.64)$ \\
Resp. House Maintenance & $0.278^{* *}$ & $(2.15)$ & $0.384^{* *}$ & $(2.36)$ \\
Resp. Outdoor Chores & 0.046 & $(0.35)$ & 0.025 & $(0.15)$ \\
Resp. Paperwork & 0.079 & $(0.58)$ & 0.066 & $(0.40)$ \\
Constant & $-5.097^{* * *}$ & $(-3.80)$ & $-6.904^{* * *}$ & $(-3.87)$ \\
\hline Log lik. & -1057.6 & & -1054.8 & \\
Chi-2 & 389.7 & & 258.6 & \\
Observations & 5522 & & 5522 & \\
\hline \hline Dependent Variable: Marital Status, $0=$ Married, $1=$ Divorce & \\
& & & &
\end{tabular}

Table 17: Clog-log analysis 


\section{Appendix 2 - Time Use Variables}

Description of the variables:

1. Urban-Rural: dummy variable, 1 if the respondent lives in an urban area, 0 otherwise;

2. Education: categorical variables: from 1 (no formal education) to 6 (university education);

3. Presence of Children: dummy variable, 1 if children younger then 18 are present in the family, 0 otherwise.

\begin{tabular}{lcccc}
\hline \hline Activity & $\mathbf{1 9 6 5}$ & $\mathbf{1 9 7 5}$ & $\mathbf{1 9 8 5}$ & $\mathbf{2 0 0 3}$ \\
\hline Work & 421.09 & 314.36 & 339.71 & 279.48 \\
Education & 10.19 & 5.42 & 4.69 & 1.40 \\
Household chores & 41.95 & 65.32 & 70.53 & 75.71 \\
Purchases & 45.37 & 37.98 & 47.87 & 56.85 \\
Child Care & 16.61 & 17.84 & 17.68 & 46.40 \\
Adult Care & 4.73 & 9.26 & 4.65 & 10.49 \\
Voluntary Activities & 15.12 & 25.32 & 16.41 & 26.82 \\
Leisure & 19.42 & 19.07 & 13.61 & 32.13 \\
Sport & 9.55 & 22.90 & 26.57 & 37.05 \\
Social Activities & 32.31 & 39.78 & 27.74 & 46.41 \\
Art & 3.96 & 4.99 & 4.03 & 1.30 \\
Relaxation & 260.27 & 273.47 & 315.37 & 300.42 \\
Travel & 17.57 & 22.96 & 22.99 & 17.00 \\
\hline \hline
\end{tabular}

Table 18: Average Time per Activity - Males 


\begin{tabular}{lcccc}
\hline \hline Activity & $\mathbf{1 9 6 5}$ & $\mathbf{1 9 7 5}$ & $\mathbf{1 9 8 5}$ & $\mathbf{2 0 0 3}$ \\
\hline Work & 110.71 & 103.68 & 147.70 & 145.73 \\
Education & 12.74 & 2.99 & 7.91 & 1.42 \\
Household chores & 266.10 & 190.78 & 188.51 & 149.53 \\
Purchases & 65.42 & 66.42 & 71.68 & 76.27 \\
Child Care & 72.89 & 56.21 & 58.97 & 94.88 \\
Adult Care & 6.66 & 12.87 & 4.66 & 14.89 \\
Voluntary Activities & 18.76 & 29.47 & 19.46 & 30.79 \\
Leisure & 18.81 & 15.30 & 13.18 & 33.05 \\
Sport & 8.90 & 18.93 & 21.67 & 25.15 \\
Social Activities & 47.94 & 57.36 & 30.53 & 52.72 \\
Art & 15.23 & 15.52 & 11.19 & 1.47 \\
Relaxation & 208.22 & 265.51 & 277.28 & 242.56 \\
Travel & 17.23 & 19.33 & 17.19 & 15.26 \\
\hline \hline
\end{tabular}

Table 19: Average Time per Activity - Females

\begin{tabular}{lccccc}
\hline \hline Variable & $\begin{array}{c}\text { Num. of } \\
\text { Observations }\end{array}$ & Mean & St. Dev. & Min. & Max \\
\hline Males & & & & & \\
Age & 126659 & 40.7715 & 10.7547 & 21 & 65 \\
Urban-Rural & 126259 & 0.7421 & 0.4375 & 0 & 1 \\
Education & 126536 & 3.8179 & 1.3279 & 1 & 6 \\
Presence of Children & 126123 & 0.6772 & 0.4676 & 0 & 1 \\
Full-time Workers & 126348 & 0.6192 & 0.4855 & 0 & 1 \\
1st Income Quartile & 126659 & 0.0884 & 0.2838 & 0 & 1 \\
4th Income Quartile & 126659 & 0.3969 & 0.4892 & 0 & 1 \\
\hline & & & & & \\
Females & & & & & 65 \\
Age & 179386 & 39.9689 & 10.6637 & 21 & 65 \\
Urban-Rural & 178915 & 0.7362 & 0.4406 & 0 & 1 \\
Education & 179334 & 3.7703 & 1.2729 & 1 & 6 \\
Presence of Children & 178257 & 0.6869 & 0.4637 & 0 & 1 \\
Full-time Workers & 179009 & 0.4233 & 0.4941 & 0 & 1 \\
1st Income Quartile & 179386 & 0.0899 & 0.2862 & 0 & 1 \\
4th Income Quartile & 179386 & 0.3835 & 0.4862 & 0 & 1 \\
\hline \hline
\end{tabular}

Table 20: List of Regressors 


\begin{tabular}{|c|c|c|c|}
\hline Males & Year 1965 & Year 1975 & Y Year 2003 \\
\hline \multirow[t]{2}{*}{ age } & $3.612^{* * *}$ & $-6.013^{* * *}$ & $-1.704^{* * *}$ \\
\hline & $(4.41)$ & $(-4.87)$ & $(-2.62)$ \\
\hline \multirow[t]{2}{*}{ age squared } & $-0.0448 * * *$ & $0.0673^{* * *}$ & $0.0153^{* *}$ \\
\hline & $(-4.49)$ & $(4.58)$ & $(2.03)$ \\
\hline \multirow[t]{2}{*}{ urban-rural } & $6.619^{* * *}$ & $-12.04^{* * *}$ & $11.96^{* * *}$ \\
\hline & $(2.64)$ & $(-3.47)$ & $(5.88)$ \\
\hline \multirow[t]{2}{*}{ kids in family } & $-30.93^{* * *}$ & $-68.78 * * *$ & $-40.79 * * *$ \\
\hline & $(-9.83)$ & $(-16.75)$ & $(-19.65)$ \\
\hline \multirow[t]{2}{*}{ education } & $-6.282^{* * *}$ & $-6.589 * * *$ & $1.533^{* *}$ \\
\hline & $(-6.49)$ & $(-5.51)$ & $(2.17)$ \\
\hline \multirow[t]{2}{*}{ fulltime job } & $23.47^{*}$ & $-108.7^{* * *}$ & $-44.67 * * *$ \\
\hline & $(1.74)$ & $(-11.51)$ & $(-16.23)$ \\
\hline \multirow[t]{2}{*}{ unemployed } & $171.6^{* * *}$ & $-59.38 * * *$ & $46.00^{* * *}$ \\
\hline & $(8.69)$ & $(-4.37)$ & $(8.79)$ \\
\hline \multirow[t]{2}{*}{ 2nd lowest quartile } & $-10.07 * *$ & 4.307 & $-10.67 * * *$ \\
\hline & $(-2.09)$ & $(0.52)$ & $(-3.24)$ \\
\hline \multirow[t]{2}{*}{ 2nd highest quartile } & $-23.68^{* * *}$ & $-22.57^{* * *}$ & $-26.01^{* * *}$ \\
\hline & $(-4.93)$ & $(-2.80)$ & $(-8.64)$ \\
\hline \multirow[t]{2}{*}{ highest quartile } & $-18.32^{* * *}$ & 11.83 & $-29.54 * * *$ \\
\hline & $(-3.69)$ & $(1.46)$ & $(-9.09)$ \\
\hline \multirow[t]{2}{*}{ spring } & $23.55^{* * *}$ & $-25.55^{* * *}$ & $-8.003^{* * *}$ \\
\hline & $(9.13)$ & $(-4.30)$ & $(-3.56)$ \\
\hline \multirow[t]{2}{*}{ summer } & 0 & $-27.75^{* * *}$ & $-12.00 * * *$ \\
\hline & . & $(-4.37)$ & $(-5.34)$ \\
\hline \multirow[t]{2}{*}{ autumn } & -2.055 & $-16.17^{* * *}$ & $-28.72^{* * *}$ \\
\hline & $(-0.59)$ & $(-2.98)$ & $(-12.88)$ \\
\hline \multirow[t]{2}{*}{ monday } & $-13.21^{* * *}$ & $18.91^{* * *}$ & $11.58^{* * *}$ \\
\hline & $(-3.22)$ & $(2.63)$ & $(3.34)$ \\
\hline \multirow[t]{2}{*}{ tuesday } & $15.79^{* * *}$ & $36.30^{* * *}$ & 1.057 \\
\hline & $(3.83)$ & $(4.89)$ & $(0.31)$ \\
\hline \multirow[t]{2}{*}{ thursday } & $24.14^{* * *}$ & $52.74^{* * *}$ & $-31.99 * * *$ \\
\hline & $(5.71)$ & $(6.66)$ & $(-9.03)$ \\
\hline \multirow[t]{2}{*}{ friday } & $14.09^{* * *}$ & $45.66^{* * *}$ & $34.48^{* * *}$ \\
\hline & $(3.25)$ & $(6.93)$ & $(9.92)$ \\
\hline \multirow[t]{2}{*}{ saturday } & $136.5^{* * *}$ & $207.3^{* * *}$ & $187.6^{* * *}$ \\
\hline & $(29.90)$ & $(31.13)$ & $(62.52)$ \\
\hline \multirow[t]{2}{*}{ sunday } & $213.8^{* * *}$ & $265.5^{* * *}$ & $230.6^{* * *}$ \\
\hline & $(49.51)$ & $(40.93)$ & $(78.41)$ \\
\hline \multirow[t]{2}{*}{ Constant } & $134.7^{* * *}$ & $520.9^{* * *}$ & $304.0^{* * *}$ \\
\hline & $(6.64)$ & $(19.94)$ & $(21.92)$ \\
\hline$R^{2}$ & 0.272 & 0.207 & 0.262 \\
\hline Adjusted $R^{2}$ & 0.271 & 0.206 & 0.261 \\
\hline Observations & 17043 & 20914 & 74200 \\
\hline
\end{tabular}

Table 21: OLS Regressions - Results for the variables not included in Table 4 


\begin{tabular}{|c|c|c|c|}
\hline Females & Year 1965 & Year 1975 & Year 2003 \\
\hline age & $\begin{array}{l}-5.013^{* * *} \\
(-7.69)\end{array}$ & $\begin{array}{l}-17.46^{* * *} \\
(-17.55)\end{array}$ & $\begin{array}{l}-9.691^{* * *} \\
(-18.42)\end{array}$ \\
\hline age squared & $\begin{array}{l}0.0644^{* * *} \\
(7.95)\end{array}$ & $\begin{array}{l}0.212^{* * *} \\
(16.97)\end{array}$ & $\begin{array}{l}0.102^{* * *} \\
(16.19)\end{array}$ \\
\hline urban-rural & $\begin{array}{l}-1.480 \\
(-0.74)\end{array}$ & $\begin{array}{l}-17.44^{* * *} \\
(-6.18)\end{array}$ & $\begin{array}{l}-11.59^{* * *} \\
(-7.01)\end{array}$ \\
\hline kids in family & $\begin{array}{l}-26.05^{* * *} \\
(-9.09)\end{array}$ & $\begin{array}{l}-40.24^{* * *} \\
(-10.69)\end{array}$ & $\begin{array}{l}-56.46^{* * *} \\
(-29.91)\end{array}$ \\
\hline education & $\begin{array}{l}-1.244 \\
(-1.33)\end{array}$ & $\begin{array}{l}-4.422^{* * *} \\
(-3.27)\end{array}$ & $\begin{array}{l}-2.829^{* * *} \\
(-4.69)\end{array}$ \\
\hline fulltime job & $\begin{array}{l}-59.85^{* * *} \\
(-25.51)\end{array}$ & $\begin{array}{l}-57.35^{* * *} \\
(-19.66)\end{array}$ & $\begin{array}{l}-30.82^{* * *} \\
(-22.03)\end{array}$ \\
\hline unemployed & $\begin{array}{l}0 \\
.\end{array}$ & $\begin{array}{l}-48.69^{* * *} \\
(-6.59)\end{array}$ & $\begin{array}{l}0.991 \\
(0.27)\end{array}$ \\
\hline 2nd lowest quartile & $\begin{array}{l}-34.95^{* * *} \\
(-9.91)\end{array}$ & $\begin{array}{l}-20.91^{* *} \\
(-2.37)\end{array}$ & $\begin{array}{l}-16.90^{* * *} \\
(-6.65)\end{array}$ \\
\hline 2nd highest quartile & $\begin{array}{l}-45.48^{* * *} \\
(-12.64)\end{array}$ & $\begin{array}{l}-19.14^{* *} \\
(-2.19)\end{array}$ & $\begin{array}{l}-18.64^{* * *} \\
(-7.90)\end{array}$ \\
\hline highest quartile & $\begin{array}{l}-39.30^{* * *} \\
(-10.65)\end{array}$ & $\begin{array}{l}-5.345 \\
(-0.60)\end{array}$ & $\begin{array}{l}-5.062^{* *} \\
(-2.01)\end{array}$ \\
\hline spring & $\begin{array}{l}14.90^{* * *} \\
(6.78)\end{array}$ & $\begin{array}{l}-27.85^{* * *} \\
(-6.11)\end{array}$ & $\begin{array}{l}2.092 \\
(1.15)\end{array}$ \\
\hline summer & 0 & $\begin{array}{l}-55.49^{* * *} \\
(-10.58)\end{array}$ & $\begin{array}{l}12.77^{* * *} \\
(7.00)\end{array}$ \\
\hline autumn & $\begin{array}{l}11.81^{* * *} \\
(4.61)\end{array}$ & $\begin{array}{l}-62.82^{* * *} \\
(-15.19)\end{array}$ & $\begin{array}{l}-17.00^{* * *} \\
(-9.32)\end{array}$ \\
\hline monday & $\begin{array}{l}-11.85^{* * *} \\
(-3.32)\end{array}$ & $\begin{array}{l}0.117 \\
(0.02)\end{array}$ & $\begin{array}{l}6.250^{* *} \\
(2.24)\end{array}$ \\
\hline tuesday & $\begin{array}{l}25.03^{* * *} \\
(7.73)\end{array}$ & $\begin{array}{l}-15.73^{* * *} \\
(-2.83)\end{array}$ & $\begin{array}{l}-17.87^{* * *} \\
(-6.45)\end{array}$ \\
\hline thursday & $\begin{array}{l}17.87^{* * *} \\
(5.32)\end{array}$ & $\begin{array}{l}-21.88^{* * *} \\
(-3.64)\end{array}$ & $\begin{array}{l}-20.09^{* * *} \\
(-7.22)\end{array}$ \\
\hline friday & $\begin{array}{l}44.11^{* * *} \\
(12.64)\end{array}$ & $\begin{array}{l}-31.54^{* * *} \\
(-5.62)\end{array}$ & $\begin{array}{l}43.99^{* * *} \\
(15.63)\end{array}$ \\
\hline saturday & $\begin{array}{l}134.5^{* * *} \\
(36.77)\end{array}$ & $\begin{array}{l}103.2^{* * *} \\
(19.37)\end{array}$ & $\begin{array}{l}175.4^{* * *} \\
(72.76)\end{array}$ \\
\hline sunday & $\begin{array}{l}220.9^{* * *} \\
(56.41)\end{array}$ & $\begin{array}{l}174.4^{* * *} \\
(33.41)\end{array}$ & $\begin{array}{l}206.1^{* * *} \\
(86.67)\end{array}$ \\
\hline Constant & $\begin{array}{l}364.4^{* * *} \\
(28.18) \\
\end{array}$ & $\begin{array}{l}757.3^{* * *} \\
(37.89) \\
\end{array}$ & $\begin{array}{l}493.8^{* * *} \\
(46.24) \\
\end{array}$ \\
\hline$R^{2}$ & 0.256 & 0.176 & 0.229 \\
\hline Adjusted $R^{2}$ & 0.256 & 0.175 & 0.229 \\
\hline Observations & 25352 & 30777 & 102482 \\
\hline
\end{tabular}

Table 22: OLS Regressions - Results for the variables not included in Table 4 


\begin{tabular}{|c|c|c|c|c|}
\hline Females & \multicolumn{2}{|c|}{$\overline{\text { Non-Working }}$} & \multicolumn{2}{|c|}{ Working } \\
\hline age & $-8.338^{* * *}$ & $(-18.29)$ & $-9.037^{* * *}$ & $(-15.96)$ \\
\hline age squared & $0.0910^{* * *}$ & (16.39) & $0.104^{* * *}$ & $(15.05)$ \\
\hline urban-rural & $-13.47^{* * *}$ & $(-9.15)$ & $-6.777^{* * *}$ & $(-4.13)$ \\
\hline kids in family & $-52.85 * * *$ & $(-26.36)$ & $-25.84^{* * *}$ & $(-14.35)$ \\
\hline education & 0.197 & $(0.33)$ & $-5.221^{* * *}$ & $(-7.82)$ \\
\hline fulltime job & 0 & & 0 & \\
\hline unemployed & $-12.17^{* * *}$ & $(-4.19)$ & $-209.0^{* * *}$ & $(-5.75)$ \\
\hline 2nd lowest quartile & $-26.63^{* * *}$ & $(-11.64)$ & $-14.03^{* * *}$ & $(-4.16)$ \\
\hline 2nd highest quartile & $-29.80^{* * *}$ & $(-13.15)$ & $-16.41^{* * *}$ & $(-5.26)$ \\
\hline highest quartile & $-33.05^{* * *}$ & $(-13.73)$ & $10.14^{* * *}$ & $(3.15)$ \\
\hline spring & $9.269^{* * *}$ & $(5.46)$ & $-8.640^{* * *}$ & $(-4.36)$ \\
\hline summer & $5.824^{* * *}$ & $(3.02)$ & $11.50^{* * *}$ & $(5.47)$ \\
\hline autumn & $-12.67^{* * *}$ & $(-7.47)$ & $-16.63^{* * *}$ & $(-8.10)$ \\
\hline$R^{2}$ & 0.216 & & 0.234 & \\
\hline Adjusted $R^{2}$ & 0.216 & & 0.234 & \\
\hline Observations & 102322 & & 75070 & \\
\hline
\end{tabular}

Table 23: OLS Regressions with Trends - Results for the variables not included in Table 8 